\title{
Functional and anatomical deficits in visceral nociception with age; mechanism of silent appendicitis in the elderly?
}

Vincent Cibert-Goton ${ }^{1}$, Victor W.S. Kung ${ }^{1}$, Cian McGuire ${ }^{1}$, James R.F. Hockley ${ }^{2}$, Michael M Tranter ${ }^{1}$, Harween Dogra ${ }^{1}$, Abi Belai ${ }^{3}$, L. Ashley Blackshaw ${ }^{1}$, Gareth J. Sanger ${ }^{1}$, Charles H. Knowles ${ }^{1}$, Eduardo J.A. Araujo ${ }^{4}$, Wendy J. Winchester ${ }^{5}$, David C. Bulmer ${ }^{1,2}$

${ }^{1}$ Blizard Institute, Barts and the London School of Medicine and Dentistry, Queen Mary University of London, London E1 2AT, UK

2 Department of Pharmacology, University of Cambridge, Cambridge CB2 1QJ, UK

${ }^{3}$ Health Sciences Research Centre, Department of Life Sciences, University of Roehampton, London, UK

4 Department of Histology, Centre of Biological Sciences, State University of Londrina, Londrina, Parana, Brazil

5 Takeda Pharmaceuticals Company Ltd, 418 Science Park, Milton Road, Cambridge, UK

Key words: Visceral pain; human; translation; nociception; afferents; ageing; colon; bowel; appendicitis

Number of pages: 40

Number of figures and tables: 12

Corresponding Author

Dr David Bulmer:

Department of Pharmacology, University of Cambridge,

Tennis Court Road, Cambridge CB2 1QJ

Email: dcb53@cam.ac.uk

Tel: $+44(0) 1223334000$

Fax: +44 (0)1223 334100

https://www.phar.cam.ac.uk/ 


\section{ABSTRACT}

The ability to sense visceral pain during appendicitis is diminished with age leading to delay in seeking healthcare and poorer clinical outcomes. To understand the mechanistic basis of this phenomenon, we examined visceral nociception in aged mouse and human tissue. Inflamed and non-inflamed appendix was collected from consenting patients undergoing surgery for the treatment of appendicitis or bowel cancer. Supernatants were generated by incubating samples in buffer and used to stimulate multiunit activity in intestinal preparations, or single unit activity from teased fibres in colonic preparations, of young and old mice. Changes in afferent innervation with age were determined by measuring the density of CGRP positive afferent fibres and by counting dorsal root ganglia back-labelled by injection of tracer dye into the wall of the colon. Finally, the effect of age on nociceptor function was studied in mouse and human colon. Afferent responses to appendicitis supernatants were greatly impaired in old mice. Further investigation revealed this was due to a marked reduction in the afferent innervation of the bowel, and a substantial impairment in the ability of the remaining afferent fibres to transduce noxious stimuli. Translational studies in human tissue demonstrated a significant reduction in the multiunit but not the single unit colonic mesenteric nerve response to capsaicin with age, indicative of a loss of nociceptor innervation. Our data demonstrates that anatomical and functional deficits in nociception occur with age, underpinning the atypical or silent presentation of appendicitis in the elderly. 


\section{INTRODUCTION}

Loss of sensory and motor activity in the bowel is thought to underlie impaired gut motility and reflex function in the elderly, and makes a significant contribution to the increased morbidity and mortality of inflammatory gastrointestinal disease with age[21;27;28].

Basic research has predominantly focused on the loss of efferent motor function in the gut with age, with evidence for neurodegenerative changes being found in both the intrinsic enteric nervous system, and the extrinsic parasympathetic and sympathetic innervation of the gut[24-26;29;32]. Although axonopathy can also be readily detected in vagal afferents innervating the gut demonstrating that changes occur in both sensory and motor components of the autonomic nervous system (ANS). Consistent with this pathology, impaired reflex function is common with advanced age particularly in pharyngoesophageal and anorectal regions, leading to an increased prevalence of dysphagia, reflux disease, constipation and faecal incontinence in the elderly[1;2; $9 ; 12]$.

By contrast to these findings, the effect of age on spinal afferents that are responsible for relaying pain from the bowel have not been extensively studied. This is surprising given the good clinical evidence for diminished abdominal pain with age. For example, pain thresholds have been shown to increase with subject age in response to noxious stimuli (distension of hollow organs) in healthy volunteers [11; $19 ; 20]$. While, atypical or silent presentation of acute painful gastrointestinal disease (e.g. appendicitis, pancreatitis, oesophagitis)[10; 12; 21], and decreased prevalence of pain in chronic gastrointestinal disease (e.g. irritable bowel syndrome or inflammatory bowel disease)[8], is found in the elderly. Clinically, the impaired ability to sense pain is thought to be a major contributing factor to the poorer prognosis and increased mortality associated with appendicitis in the elderly due to delayed symptom presentation, typically with more advanced disease[12; 21].

Our current mechanistic understanding of the effects of age on visceral nociception is conflicting. Data from animal studies indicates that functional deficits in stimulus transduction, as opposed to a loss of innervation, are predominantly responsible for diminished nociception in old mice[18,24,25]. For example, studies using CGRP as a marker of spinal afferent fibres demonstrated no change in the density of innervation, and limited axonal pathology in submucosal and myenteric layers of the gut with age in rats[24; 25]. While afferent response to noxious distension of the intestine, and capsaicin were diminished in aged mice[18]. By contrast, a comprehensive study looking at single unit responses in human colonic nociceptors showed no difference 
in the response to local application of bradykinin, ATP or mechanical probing with von Frey hairs compared with the age of the patient from which the tissue was obtained[22]. Further work is now needed to put these observations into context with clinical findings. To that end, we examined the effects of ageing on the afferent innervation of the mouse gut, and the response of mouse and human intestinal afferents to noxious and inflammatory stimuli, including responses to supernatants generated from inflamed human appendix.

\section{METHODS}

\section{Human tissue: Appendix}

Ethical approval was granted by the East London and the City HA Local Research Ethics Committee (NREC 10/H0703/71). Resected inflamed appendix were obtained from consenting patients undergoing appendectomy as part of their standard clinical treatment for appendicitis at Barts Health NHS Trust, London (Table 1). Control, macroscopically normal appendix were obtained following pathological examination, from consenting patients undergoing right hemicolectomy as part of their standard clinical treatment for bowel cancer (Table 1).

\section{Supernatant generation}

The closed end of the appendix was cut open and the lumen flushed with $10 \mathrm{ml}$ of freshly prepared carbogenated $\left(95 \% \mathrm{O}_{2}, 5 \% \mathrm{CO}_{2}\right)$ Krebs buffer (in $\mathrm{mM}: 124 \mathrm{NaCl}$, $4.8 \mathrm{KCl}, 1.3 \mathrm{NaH}_{2} \mathrm{PO}_{4}, 2.5 \mathrm{CaCl}_{2}, 1.2 \mathrm{MgSO}_{4} .7 \mathrm{H}_{2} \mathrm{O}, 11.1$ glucose, and $25 \mathrm{NaHCO}_{3}$ ) at room temperature. The tissue sample was subsequently incubated in a fixed volume $(2.5 \mathrm{ml} / \mathrm{g})$ of Krebs buffer at $37^{\circ} \mathrm{C}$ for 25 minutes. Following which the tissue was removed, the remaining buffer centrifuged at $2000 \mathrm{rpm}$ for $10 \mathrm{~min}$ to remove debris, and the supernatant carefully removed and stored in $0.5 \mathrm{ml}$ aliquots at $-80^{\circ} \mathrm{C}$ until use.

\section{Cytokine quantification and analysis}

Quantitative analysis of protein cytokines levels in the appendix supernatants was performed using established capture sandwich immunoassay and magnetic microsphere methodology. Samples were prepared as per manufacturer's instructions using custom multiplex assay kits for IL-1 beta, IL-2, IL-6, CXCL8, and TNF- alpha (Invitrogen, UK), and analysed using the Luminex MAGPIX ${ }^{\circledR}$ detection system (Luminex, TX, USA).

Cytokine levels were compared between supernatants from inflamed and control appendix using a Student's t-test, significance set at $p<0.05$. Correlations of the 
cytokine levels with patient's age were performed using a Spearman's rank-order test. Significance was set at $p<0.05$.

\section{Mouse electrophysiological studies}

Electrophysiological studies were performed on tissue from young female (3 months) and old (24 months) female and male C57BI6 mice. Studies examining the effect of inflamed and non-inflamed human appendix supernatant on intestinal mesenteric nerve activity and the effect of colorectal distension on lumbar splanchnic nerve activity were performed in tissue from young and old male and female mice. All other studies were performed using tissue from young and old female mice only. Mice were euthanized by rising concentration of $\mathrm{CO}_{2}$, followed by cervical dislocation in accordance with Schedule 1 of the Animals Scientific Procedures Act (1986). All experiments were performed blinded to the age of the animals.

\section{Multiunit recordings}

To investigate the effects of ageing on intestinal afferent mechanosensitivity and chemosensitivity within mesenteric or lumbar splanchnic nerve bundles, mulitunit nerve activity was recorded from tubular small intestine, or colorectal preparations, in vitro as described previously[13; 14; 18]. Small intestine with associated mesenteric arcades or distal colon with associated lumbar splanchnic nerves were removed, and placed in cold carbogenated Krebs buffer supplemented with nifedipine (10 $\mu \mathrm{M})$, atropine $(10 \mu \mathrm{M})$, and indomethacin $(3 \mu \mathrm{M})$ were performed as described previously (see supplemental methods for further details). A $3 \mathrm{~cm}$ section of the small intestine, or a $4 \mathrm{~cm}$ segment of colorectum (taken from the anus to descending colon) was placed in a $10 \mathrm{ml}$ volume tissue bath and perfused with supplemented carbogenated Krebs buffer $\left(7 \mathrm{ml} / \mathrm{min} ; 32-34{ }^{\circ} \mathrm{C}\right)$. The tissue was cannulated at both ends and luminally perfused with supplemented Krebs $(0.1 \mathrm{ml} / \mathrm{min})$. Intestinal mesenteric or colonic lumbar splanchnic (rostral to the inferior mesenteric ganglia) nerves were carefully dissected free and ongoing nerve discharge recorded using a borosilicate glass pipette suction electrode. Electrical signals were amplified (Neurolog; gain $5 \mathrm{~K}$ ), band pass filtered (Neurolog; $100-1300 \mathrm{~Hz}$ ), digitally filtered (Humbug; $50 \mathrm{~Hz}$ ) and digitised (Cambridge Electronic Design, CED; $20 \mathrm{KHz}$ ) for recording to computer using Spike 2 software (CED).

\section{Protocols}

Following a minimum 30min stabilisation period intestinal preparations were bath perfused with $3 \mathrm{ml}$ of inflamed appendicitis supernatant in tissue from young and old animals, or $3 \mathrm{ml}$ of control non-inflamed appendix supernatant in separate tissue from 
young animals. In a separate set of animals, the response to bath perfusion with 20 $\mathrm{ml}$ of bradykinin $(1 \mu \mathrm{M})$ was also examined in young and old animals. In colonic preparations ramp distensions were achieved by occluding the luminal outflow, which resulted in an increase in luminal pressure in response to the continuing luminal perfusion $(0.1 \mathrm{ml} / \mathrm{min})$. The pressure was allowed to rise up to a distension of 80 $\mathrm{mmHg}$ after which the outflow was reopened and the luminal pressure returned to 0 $\mathrm{mmHg}$.

\section{Data analysis}

Neuronal firing rates were examined offline using data analysis software in Spike 2 (CED, UK) and action potentials passing a threshold level set at twice the noise level were counted.

For changes in nerve discharge following the application of bradykinin or supernatants derived from inflamed and non-inflamed appendix to intestinal preparations, nerve discharge was displayed as a mean frequency (60s time base) in spikes/s. From this mean frequency plot, peak baseline activity was measured over a 3 min period immediately preceding perfusion of the test substance, and the peak increase in nerve activity following test perfusion was determined by subtracting this peak baseline value from the maximum nerve activity measured over the $15 \mathrm{~min}$ period of time following test perfusion.

For changes in nerve discharge following ramp distension of colonic preparations, ongoing nerve discharge was displayed as mean frequency (10s time base) in spikes/s. From this mean frequency plot, the peak baseline $(0 \mathrm{mmHg})$ nerve discharge was measured over the 3 min period before ramp distension and the increase in nerve discharge calculated at $10 \mathrm{mmHg}$ pressure intervals up to 80 $\mathrm{mmHg}$, by subtracting the baseline activity from the ongoing nerve discharge measured at each respective pressure (eg 10, 20,30,40,50,60,70, $80 \mathrm{mmHg}$ ). Changes in compliance between tissues from old and young animals were also compared during ramp distension by calculating the volume of fluid infused from the time taken to increase intraluminal pressure at $10 \mathrm{mmHg}$ pressure intervals up to 80 $\mathrm{mmHg}$.

Values were expressed as a mean \pm standard error of mean (SEM) and statistically compared between tissues from young and old animals using an unpaired Student's t-test or two-way ANOVA (with Bonferroni's post hoc comparison of individual data points) as appropriate, significance set at a $p$ value of $<0.05$.

\section{Teased fibre recordings}


To investigate the effect of age on mechanosensitivity and chemosensitivity within individual nerve fibres, single unit activity was discriminated from teased fibre recordings of lumbar splanchnic nerve activity in flat sheet preparations of the colorectum as described previously $[13 ; 15]$. The distal colorectum $(4 \mathrm{~cm}$ in length taken from anus to descending colon) was opened along the anti-mesenteric border and pinned flat serosa up to allow supernatant application directly to the serosal surface of the gut. Lumbar splanchnic nerves (LSN) were dissected free rostral to the inferior mesenteric ganglia and thin bundles of fibres carefully teased free to facilitate recording of activity from a few active units with glass pipette suction electrodes as described above.

\section{Protocol}

Preparations were first systematically searched by probing of the serosal surface of the colon and mesentery with a 0.6 gram von Frey hair (VFH, Ugo Basile, IT) and the number of every receptive fields (RF) whose probing consistently (responsive on 3 separate occasions) generated action potential (AP) firing, noted. Units were characterised as mesenteric if they responded to probing of the mesentery, muscular if they responded to tissue stretch following application of a $5 \mathrm{~g}$ weight to the tissue via a metal tissue claw and pulley system, and serosal if they only responded to VFH probing of the serosal surface and not tissue stretch, comparable with the classification first proposed by Brierley et al[5]. It is however noted that these definitions may not reflect the likely site of afferent terminations which could lie in deeper layers of the gut to which stimulus was applied. Serosal and mesenteric fibre types are considered to be putative nociceptors, based on their response to high threshold mechanical stimuli and noxious algogenic mediators[4; $6 ; 7 ; 16 ; 22]$.

Following the mapping of receptive fields mechanosensitivity and chemosensitivity was tested in serosal units only.

First the baseline mechanosensitivity to probing was quantified by probing the receptive field with $0.6 \mathrm{~g}$ and $1.0 \mathrm{~g} \mathrm{VFH}$ (each consisting of 3 successive probes applied for $3 \mathrm{~s}$ at intervals of $60 \mathrm{~s}$ ). A metal ring was then placed over the receptive field, the Krebs within the ring carefully removed and $100 \mu \mathrm{L}$ of test substances applied to the ring. Changes in activity were determined in young and old mice following the application of appendicitis supernatants (12min application), experimental inflammatory soup ( $1 \mu \mathrm{M}$ bradykinin, $1 \mathrm{mM}$ ATP, $10 \mu \mathrm{M}$ histamine, 10 $\mu \mathrm{M}$ prostaglandin $\mathrm{E}$ and $10 \mu \mathrm{M} 5-\mathrm{HT} ; 5$ min application) or bradykinin (0.3 and 1.0 $\mu \mathrm{M}$ given $10 \mathrm{~min}$ apart for $5 \mathrm{~min}$ ) in separate experiments. Mechanosensitivity was re-tested $(0.6 \mathrm{~g}$ and $1.0 \mathrm{~g} v \mathrm{Fh}) 2 \mathrm{~min}$ after removal of the test substance.

\section{Data analysis}


Data was analysed from individual single unit discharge, discriminated offline using template matching wavemark software (Spike 2). For mechanosensitivity to VFH probing, peak action potential discharge was determined over a $2 \mathrm{~s}$ period within the 3s period of probing for each probe. These values were then averaged to produce a mean response for each set of 3 probes. For chemosensitivity to test substances, action potential discharge of individual fibres was counted over the incubation period of the stimulus (e.g. $12 \mathrm{~min}$ for appendicitis supernatant, $5 \mathrm{~min}$ for inflammatory soup or bradykinin). This value was then expressed as a change in total activity over the test period by subtracting an estimated value for baseline activity over the test period extrapolated from the ongoing activity measured 3min prior to incubation with the test substance (i.e. the estimated baseline activity over the appendicitis supernatant test period was calculated by multiply the total ongoing activity $3 \mathrm{~min}$ prior to application by 4$)$. Values are expressed as a mean \pm SEM and statistically compared between groups using Student's t-test, significance determined as a $p$ value of $<0.05$.

\section{Mouse anatomical studies}

\section{Small intestine whole mounts}

The mesenteric tissue was collected from young ( 3 month, $n=4)$ and old (24 month, $\mathrm{n}=4$ ) female C57BI6 mice, euthanized by rising concentration of $\mathrm{CO} 2$, followed by cervical dislocation in accordance with schedule 1 of the Animals Scientific Procedures Act (1986). The tissue was immediately placed in phosphate buffered saline (PBS, $0.1 \mathrm{M} \mathrm{pH} \mathrm{7.4)} \mathrm{containing} 4 \%$ paraformaldehyde (PFA) for fixation (24 hours). Each tissue was processed to obtain whole mounts, which were submitted to immunofluorescence protocol for the labelling of CGRP+ fibres. Whole mounts were washed in $1 \%$ triton-PBS and kept in blocking solution for $1 \mathrm{~h}$. Following which whole mounts were incubated in primary antibody (Goat anti-CGRP antibody (Abcam AB36001) at a dilution of 1: 400 in blocking buffer (1\% Triton, $10 \%$ goat serum in PBS). Whole mounts were washed again in $1 \%$ Triton-PBS, and incubated in secondary antibody (488 Donkey anti-goat antibody (Invitrogen A11039) at a dilution of 1: 500) in 1\% triton-PBS for $2 \mathrm{~h}$ at room temperature, following which whole mounts were washed in $1 \%$ triton-PBS and mounted using Vectashield Mounting HardSet.

\section{Data analysis}

Pictures were acquired on an Olympus BX61 fluorescent microscope (Olympus Corp., Japan) equipped with a Hamamatsu ORCA-ER digital canera C4742-80 (Hamamatsu Photonics K.K., Japan) using Smartcapture V3. Ten randomized images were acquired from each whole-mount, patterning the light incidence 
(Exposure: 210ms; Saturation: 1,5; Gamma: 1.25; and Gain: 2.0x). All images were analysed blind to the age of the animals. Images were saved as JPEG files and analysed for CGRP labelling brightness intensity as an indicator of the density of fibres using ImageJ analysis software v1.45S ( $\mathrm{NIH}$, USA). The peak fluorescent intensity (no background subtraction) observed was measured in each image over individual mesenteric nerve bundles and averaged to produce a mean value for each animal. Values from each animal were then averaged to produce mean values for young and old animals respectively. Data is expressed as Mean \pm SEM values for tissue from young and old mice, and statistically compared between young and old animals using student t-test significance set at $p<0.05$.

\section{Retrograde labelling of colonic sensory neurones}

Young ( 3 months, $n=6$ ) and old ( 24 months, $n=6$ ) female C57BI6 mice were used. Mice were anaesthetised ( $1.5 \%$ isofluorane), and a mid-line laparotomy performed to expose the gastrointestinal tract. The small intestine was gently reflected using cotton tips to expose the distil colon and rectum. Fast Blue (FB; $2 \%$ in saline, Polysciences Gmbh, Germany) was then injected into the wall of the distal colon at 5 different sites $(0.2 \mu \mathrm{l}$ each) as previously described[13], the laparotomy closed and animals allowed to recover from anasethesia. Post-operative analgesia was provided daily (buprenorphine $0.05-0.1 \mathrm{mg} / \mathrm{kg}$ subcutaneously) for 3 days, and five days after surgery mice were deeply anesthetized with sodium pentobarbital $(140 \mathrm{mg} / \mathrm{kg}$, intraperitoneally) and perfused transcardially with saline $(0.9 \% \mathrm{NaCl})$ followed by $0.1 \mathrm{M} \mathrm{pH} 7.4$ phosphate buffer (PB) containing 4\% PFA. To look at changes in the innervation by splanchnic spinal afferents, the left and right T13 thoracic and L1 lumbar dorsal root ganglia (DRGs) were then dissected and post fixed in $4 \%$ PFA overnight. The following day tissues were transferred in $30 \%$ sucrose (w/v phosphate buffered saline) for $24 \mathrm{~h}$ at $4^{\circ} \mathrm{C}$ and then blocked in O.C.T. (Optimum Cutting Temperature) embedding matrix (BDH, Essex, UK) in liquid nitrogen and stored at $-80^{\circ} \mathrm{C}$. $10 \mu \mathrm{m}$ thick transverse sections of T13 and L1 DRGs (perpendicular to the neuronal axis of the DRG) were cut on a Bright microtome 5040, mounted on slides (Superfrost Plus, BDH) sequentially, allowed to dry at room temperature for $30 \mathrm{~min}$ and then processed for immunohistochemistry. 4 slides from each animal (1slide per DRG) were used for the staining.

\section{Data analysis}

Sections were imaged (Olympus BX61 fluorescent microscope, Hamamatsu ORCAER digital camera, Smartcapture V3 software). Images (20x) for Fast Blue (FB; filter) and the general nuclear marker 4',6-diamidino-2-phenylindole (DAPI filter) were 
taken of 2 to 5 sections per DRG level (i.e. T13 and L1) for each animal. Pictures were analysed using ImageJ $1.45 \mathrm{~S}$ analysis software, blinded to the age of the animals. All DRG cells with visible nuclei positive for DAPI and all FB positive cells were counted in each section. L1 and T13 data were averaged and the mean percentages of colon projecting neuronal cell bodies versus total population numbers established in both groups for statistical comparison using the student t-test. Data are expressed as mean \pm SEM. $p$ value of $<0.05$ considered significant.

\section{Human colon electrophysiological studies}

Macroscopically normal full-thickness human colon was obtained from consenting patients (NREC 10/H0703/71) undergoing surgery as part of their standard clinical treatment for bowel cancer (Table 2). All tissues used were surplus to further clinical requirement, following pathological examination and taken, away from any tumour or resection margins. Tissue were kept in cold carbogenated Krebs buffer following surgical resection.

\section{Multiunit recordings}

Mesenteric nerve activity was recorded from flat sheet preparations of human colon as previously described[15;22]. Briefly tissue was pinned flat (serosa up) in a bespoke recording chamber superfused with carbogenated Krebs buffer $(6 \mathrm{ml} / \mathrm{min}$ at $\left.32-34{ }^{\circ} \mathrm{C}\right)$ supplemented with atropine $(10 \mu \mathrm{M})$ and nifedipine $(10 \mu \mathrm{M})$. Nerve bundles were identified within the free mesenteric attachment along major blood vessels, and neuronal activity was recorded as described above for the mouse experiments. Mediators were applied to the $100 \mathrm{ml}$ tissue bath by superfusion of a $20 \mathrm{ml}$ volume of: BK $(10 \mu \mathrm{M}$ solution for a final bath concentration of $2 \mu \mathrm{M})$, ATP $(10 \mathrm{mM}$ solution / $2 \mathrm{mM}$ bath), or capsaicin (10 $\mu \mathrm{M}$ solution / $2 \mu \mathrm{M}$ bath).

\section{Data analysis}

Neuronal firing rates were examined offline using data analysis software in Spike 2 (CED, UK). Action potential discrimination threshold was set at twice the noise levels. Ongoing nerve activity (action potentials discharge) was expressed as a rate histogram (20s bin width). Individual single units were also discriminated offline using template matching software in Spike 2 allowing whole nerve and single unit analysis of colonic afferent response to algogenic mediators. Changes in afferent activity following mediator application were determined by subtracted the baseline activity (average firing rate over the 100s period prior to mediator application) from the peak firing rate observed in the rate histogram within 10 minutes of mediator application. Positive responses were defined as a maintained increase $(>25 \%)$ in action potential firing above baseline levels. When more than a single mediator was applied a post- 
drug washout of 60 minutes was observed although in the absence of a response, the next mediator was applied after only 30 minutes. Correlations of the change in afferent activity with patient's age were performed using a Spearman's rank-order test. Significance was set at $p<0.05$.

\section{RESULTS}

\section{The ability of visceral afferents to sense appendicitis is reduced with age.}

The perception of pain during appendicitis is diminished in the elderly, suggesting that visceral nociception may be impaired with age. To investigate this further we measured the effect of supernatants generated from inflamed human appendix on intestinal mesenteric nerve activity. We observed a robust increase in activity in tissue from young mice $(7.7 \pm 0.6$ spikes/s, $n=8$ nerves $)$, which was substantially reduced in tissue from old mice ( $2.2 \pm 0.5$ spikes $/ \mathrm{s}, \mathrm{n}=8$ nerves, $p<0.005$; the same supernatants were tested in tissue from young and old mice) (Figure 1, A \& B), demonstrating that the afferent response to appendicitis is greatly diminished with age. Control supernatants generated from normal appendices, produced, minor transient changes in nerve activity ( $3.8 \pm 0.8$ spikes $/ \mathrm{s}, \mathrm{n}=5$ nerves) (Figure $1, A \& B$ ). No difference was observed in the afferent response to supernatants (non-inflamed or inflamed appendix) generated from male compared with female patients (Figure 1, $B)$; and no correlation was observed between the age of the patient from which a supernatant was obtained and the magnitude of its stimulatory effect on intestinal mesenteric nerve activity (supplemental Figure 1, A).

Baseline ongoing nerve discharge was not significantly different between mesenteric nerves in tissue from young mice tested with non-inflamed supernatant $(18.1 \pm 3.5$ spikes/s, $n=5$ nerves), young mice tested with inflamed appendicitis supernatant (14.5 \pm 1.5 spikes/s, $n=8$ nerves) and old mice tested with inflamed appendicitis supernatant $(15.5 \pm 1.5$ spikes $/ \mathrm{s}, \mathrm{n}=8$ nerves) $(\mathrm{p}=0.50$ one-way ANOVA). Furthermore, no difference was observed in the afferent response to non-inflamed supernatant and inflamed appendicitis supernatant in tissue from young male compared with young female mice, and inflamed appendicitis supernatant in tissue from old male compared with old female mice (supplemental Figure 1, B).

Consistent with the presence of inflammatory disease in appendicitis, significant increases in cytokine levels were detected in the supernatants from inflamed (e.g. CXCL8; $58.6 \pm 18.6 \mathrm{pg} \mathrm{ml}^{-1}, \mathrm{n}=5$ supernatants, $\left.\mathrm{p}<0.05\right)$ compared with normal appendices (7.4 $\pm 2.1, \mathrm{pg} \mathrm{ml}^{-1} \mathrm{n}=5$ supernatants) (Figure $1 \mathrm{C}$ ). No correlation was 
observed between the patient's age, and supernatant mediated nerve discharge or cytokine levels (supplemental Figure 2).

The terminal ileum is innervated by vagal afferents and spinal afferents running with the splanchnic nerves, with pain arising from the activation of spinal afferents by noxious stimuli. To understand the nature of the blunted afferent response to appendicitis supernatants further, we looked at the effect of age on the afferent response to bradykinin. The intestinal afferent response to bradykinin has previously been shown to be preserved following chronic vagotomy suggesting that it is predominantly mediated by spinal compared with vagal afferents innervating the small intestine[3]. Responses to bradykinin were substantially attenuated in tissue from old $(18.3 \pm 2.2$ spikes/s, $n=10$ nerves, $p<0.005)$ compared with young mice $(46.5 \pm 6.0$ spikes/s, $n=10$ nerves) (Figure $1, D \& E)$, indicating that spinal afferent signalling is impaired in elderly mice, and suggesting that a deficit in spinal afferent nociception may have contributed to the reduced response to appendicitis supernatants in aged tissue.

\section{The innervation of the bowel by nociceptors is diminished with age}

To determine if a loss in spinal nociception with age was due to a reduction in afferent innervation we examined the afferent innervation of the small intestine utilised CGRP immunoreactivity as a marker of afferent innervation in the outer layers of the gut and mesentery (Figure $2 \mathrm{~A}$ ). We observed a substantial reduction in the density of CGRP positive fibres within serosal and mesenteric layers of the small intestine, in tissue from old $(10.4 \pm 2.5$ fluorescence units, $n=10$ images, $p<0.05)$ compared with young mice (16.7 \pm 4.3 , fluorescence units, $n=10$ images) (Figure $2 \mathrm{~B})$. This observation was supported by the significant reduction seen in the percentage of splanchnic spinal afferent cell bodies (located in thoracolumbar DRGs) labelled per section by retrograde transport of fast blue tracer injected into the colon wall of old $(3.9 \pm 0.5, n=12$ sections, $p<0.005)$ compared with young mice $(8.3 \pm 0.8$, $\mathrm{n}=12$ sections) (Figure $3, A \& B$ ). In addition, the total number of thoracolumbar DRG cell bodies was also found to be significantly reduced in old $(130.9 \pm 9.3$ cell bodies per section, $n=12$ sections, $p<0.05)$ versus young mice $(165.5 \pm 9.8, n=12$ sections).

Further, functional evidence of a significant reduction in the splanchnic spinal innervation of the colon was also seen by the paucity of receptive fields (RFs) found in the serosa (young, $3.4 \pm 0.6$ RFs per nerve bundle, from $n=11$ bundles in $n=7$ mice vs old, $1.7 \pm 0.3$ RFs per nerve bundle, from $n=12$ bundles in $n=5$ mice $p<0.05$ ) and mesentery (young, $5.1 \pm 0.7$ RFs per nerve bundle, from $n=10$ bundles in $n=5$ 
mice vs old, $2.2 \pm 0.8$ RFs per nerve bundle, from $n=6$ bundles in $n=3$ mice $p<0.05$ ) (Figure $3 \mathrm{C}$ ) by systematic probing of flat sheet colonic preparations in electrophysiological studies of lumbar splanchnic nerve activity using tissue from old compared with young mice. Colonic afferents with mesenteric and serosal receptive fields have previously been shown to function as nociceptors suggesting that the loss of spinal afferent innervation seen in our study would impair nociception[4-7; 17].

To test this, we first examined the colonic afferent response in the lumbar splanchnic nerve to luminal ramp distension, observing a marked impairment in the afferent response to high threshold distension of the bowel at pressures $(40-80 \mathrm{mmHg}$ ), associated with the perception of pain in humans in tissue from old compared with young mice (Figures 4, A-B). The colonic afferent responses at lower distending pressures (0-30 $\mathrm{mmHg}$ ) were comparable between tissue from old compared with young mice (Figure 4B), demonstrating a selective effect of ageing on visceral nociception. Colonic compliance was also increased with age at all distending pressures, significantly from $30-80 \mathrm{mmHg}(p<0.05$; Figure $4 \mathrm{~A} \& \mathrm{C})$. The same pattern of response with age (significant reduction in colonic afferent activity at high threshold distending pressure and increase in colonic compliance at all pressures) was observed in tissue from female compared with male mice, although the increase in gut compliance was notably larger in tissue from aged female mice (supplemental Figure 3).

In contrast to luminal distension, the single unit afferent response to VFH probing (0.6 and $1 \mathrm{~g})$ of serosal receptive fields of putative colonic nociceptors was comparable in old and young tissue ( $p>0.05$; Figure $5, A \& B$ ), suggesting that the reduced multiunit nerve response to noxious ramp distention may be due to a loss of nociceptor innervation compared with an inability to transduce mechanical stimuli at the level of the afferent fibre ending.

\section{The ability of nociceptors to transduce inflammatory algogenic stimuli is greatly diminished with age}

To understand if the transduction of algogenic inflammatory stimuli is impaired with age we next examined single unit colonic afferent responses in the lumbar splanchnic nerve to bradykinin (300nM and $1 \mu \mathrm{M})$ (Figure 6, A \& B), and an experimental inflammatory soup containing multiple mediators (Figure 6, C \& D); observing a substantial reduction in the afferent response to either $\mathrm{BK} 1 \mu \mathrm{M}$ (young, $471.3 \pm 107.7$ spikes, $n=5$ fibres vs old, $152.4 \pm 33.9$ spikes, $n=5$ fibres; $p<0.05$ ), and the experimental inflammatory soup (young, $684.6 \pm 156.4$ spikes, $n=10$ fibres vs old, $232.9 \pm 21.7$ spikes, $n=7$ fibres; $p<0.05$ ) in tissue from old compared with 
young mice. Finally, to confirm a disease relevance to these changes we examined the afferent response to appendicitis supernatant (Table 1; Figure 7, A \& B) observing a marked reduction in the activation of colonic afferents in tissue from old mice $(48.5 \pm 22.6$ spikes, $n=5$ fibres, $p<0.05)$ compared with the robust response in young mice (201.4 \pm 46.4 spikes, $n=7$ fibres). No difference was observed in the magnitude of the colonic afferent response to appendicitis supernatants generated from female compared with male patients. Interestingly, the ability of appendicitis supernatants to sensitise VFH probing of colonic afferents was also attenuated in tissue from old mice $(8.2 \pm 0.6$ vs $11.4 \pm 1.1$ spikes $/ s, n=4$ fibres, $p<0.05$, pre vs post appendicitis supernatant in young mice; compared with $5.3 \pm 1.9$ vs $6.9 \pm 2.4$ spikes/s, $n=4$ fibres, $p>0.05$, pre vs post appendicitis supernatant in old mice; Figure $7, C \& D)$. Although, the basal response to VFH probing was comparable between old and young tissues ( $p>0.05$ ), suggesting that stimulus specific deficits exist in the signalling of the remaining colonic nociceptors with age.

\section{Translation to human nociceptors}

To translate these findings on ageing to human visceral nociception we examined the effect of age on changes in multiunit mesenteric nerve activity in human colon following application of bradykinin, ATP, and capsaicin. Consistent with a deficit in visceral nociception with age we found a marked reduction in the afferent response to capsaicin in tissue for elderly patients (Figure $8 \mathrm{~A}$ ), producing a significant negative correlation between the colonic afferent response to capsaicin and the patient's age (Figure 8B, $r=-0.68, p<0.05, n=11$ tissues). A similar trend could clearly be seen for the colonic afferent response to bradykinin, although this did not reach significance (Figure $8 \mathrm{C}, \mathrm{r}=-0.53, \mathrm{p}=0.11, \mathrm{n}=10$ tissues). By contrast no correlation was found between the patient's age, and the colonic afferent response to ATP (Figure 8D, $r=-$ $0.10, p=0.78, n=10$ tissues) or ongoing baseline colonic nerve discharge prior to treatment (Figure 8E, $r=0.09, p=0.72, n=19$ tissues). It is notable from the data in table 2 that both the youngest and eldest patients responsive to bradykinin or capsaicin did not receive chemotherapy or radiotherapy prior to surgery. As such it is unlikely that the loss of nerve firing seen in response to capsaicin or bradykinin with age was due to chemotherapy or radiotherapy prior to surgery. Furthermore, no observable difference was seen in the human colonic afferent response to the mediators tested or ongoing baseline nerve discharge between tissues from female compared with male patients.

In contrast to the reduced multiunit response to capsaicin with age, the response of individual single units discriminated from the multiunit recording, to capsaicin was 
comparable across the patients age range (Figure 9A, $r=0.21, p=0.74, n=5$ units). This suggests that the reduced multiunit response to capsaicin was mediated by a loss of innervation as opposed to a reduction in the ability of colonic afferents themselves to respond capsaicin. Additionally, there was also no correlation between the patient's age and the afferent response to bradykinin, ATP or baseline firing, in single units discriminated from the multiunit nerve recordings (e.g. bradykinin Figure 9B, $r=-0.13, p=0.79, n=7$ units), ATP Figure $9 \mathrm{C}, r=0.13, p=0.79, n=7$ units, and at baseline Figure 9D, $r=0.21, p=0.47, n=12$ units).

\section{DISCUSSION}

Abdominal pain is less frequently reported with age across gastrointestinal disorders, suggesting that disease nociception is impaired in the elderly[10; 12; 21]. During inflammatory disease, this may be due to reduced release of pro-nociceptive mediators with age, however healthy volunteer studies in humans showing reduced sensitivity to oesophageal and colorectal distension[19; 20], and decreased sensations of pain, nausea, and fullness with age[11] indicate a loss of nociceptor function and pain signalling with age irrespective of stimulus. Despite the clinical evidence for reduced pain perception with age, experimental studies demonstrating functional and anatomical correlates of altered nociceptor signalling with ageing in the gut are lacking, and discrepancies exist in current data from mouse and human tissue[18; 22].

To address this, we examined the effect of supernatants generated from inflamed human appendix (appendicitis) on mesenteric nerve activity in the terminal ileum of young and old mice observing a significantly reduced afferent responses in tissue from old mice. Similar observations of a greatly reduced response in tissue from old mice to bradykinin, a potent stimulus of spinal nociceptors in the gut[3], suggesting a reduction in the splanchnic spinal innervation of the bowel.

To examine this further we studied the intensity of CGRP labelling in serosal and mesenteric layers of the small intestine seeing a significant reduction in the density of CGRP positive labelling. However, CGRP is not a definitive marker of spinal afferents and may also label enteric neurones or vagal afferents[25], and so to confirm this observation we also examined the number of splanchnic thoracolumbar DRG neurones back labelled following tracer injection of fast blue into the wall of the distal colon. These studies, demonstrated a significant reduction in the number of fast blue positive neurones DRGs in tissue from old mice consistent with reduced spinal 
afferent innervation with age. These findings are in keeping with previous reports of reduced CGRP and substance $P$ immunoreactivity in thoracolumbar DRG neurones in old rats[23], but contrast with reports of unchanged CGRP labelling within the muscle layers of the rat large intestine with age[25], suggesting that ageing may have differential effects on anatomically and functionally distinct spinal afferent fibre populations, or that the effects of ageing may differ across different parts of the GI tract.

To explore the effect of ageing on different spinal afferent populations, we next examined the splanchnic afferent responses to ramp distension of the colon, observing a marked reduction in the afferent response to noxious distending pressures $(40-80 \mathrm{mmHg})$, consistent with a selective effect of ageing on colonic nociceptors compared with afferents that transduce lower threshold mechanical stimuli in keeping with previous reports by Keating et al[18]. We also observed an increase in colonic compliance with age. This was seen at all pressures, suggesting that the change in compliance may not be responsible for the reduced afferent response to distension in tissue from old mice. However, the relationship between compliance changes and the ability of afferent endings to transduce mechanical stimuli is complex, and so further work is required to confirm that the loss of mechanosensitivity at higher distending pressures is not due to a difference in the effect of compliance changes.

To study the effects of ageing on individual visceral nociceptors further, we utilised a flat sheet preparation originally developed by Brierley et al[5]; using this preparation to study two anatomically distinct splanchnic afferent populations, mesenteric and serosal afferents, with presumptive nociceptor function, based on their response to noxious mechanical and chemical stimuli. Recent studies using antereograde tracing techniques suggests that the distribution of afferent fibres defined as serosal based on these criteria may not necessarily be restricted to the serosal layer[30]. However, the classification system of Brierley remains an approach to distinguish functionally distinct colonic afferent populations, for which a large body of information is known. These studies demonstrated a substantial reduction in the number of serosal and mesenteric receptive fields of colonic afferents in tissue from old mice, providing further evidence of reduced nociception with age in mice. Interestingly the magnitude of the response to VFH probing of the receptive fields, for the units present in tissue from old mice, was comparable to that seen in young. This is consistent with our previously study demonstrating that the magnitude of responses to VFH probing of human serosal nociceptors are similar irrespective of the patient's age[22]. These findings to VFH probing suggest that a loss of innervation contributes to the blunted 
afferent response to noxious ramp distending pressures, although differences in the density of innervation and response characteristics of units responding to VFH probing compared with luminal distension of the colon may also be important. In addition to mechanical stimuli we also examined responses to noxious chemical mediators, including appendicitis supernatants, observing greatly attenuated responses in tissue from old mice. Age-related reduction in the afferent response to appendicitis is mediated by both a loss of nociceptor innervation, and an impaired ability of the remaining nociceptors to transduce noxious mediators released from the inflamed appendix.

Finally, to understand if similar age-related changes in nociception occur in the human bowel, we compared ongoing baseline nerve discharge, and the afferent response to ATP, bradykinin or capsaicin, with the patient's age in mesenteric nerve recordings from the human colon. Consistent with a selective effect of ageing on nociception, we found a significant decrease in the multiunit colonic afferent response to the algogenic mediator capsaicin, and a reduction in the response to bradykinin. By contrast no effect of ageing was seen on baseline nerve discharge, a property we found more frequently in human muscular afferents (sensitive to tissue stretch), by comparison with human serosal nociceptors (insensitive to tissue stretch) that are typically silent at rest[22]. The human colonic afferent response to ATP was also found to be unchanged with ageing. The implication of this finding is unclear. We have previously shown that ATP sensitivity is a property of serosal nociceptors and not muscular afferents in human preparation[15; 22]. A reduction of the afferent response to ATP with age might therefore be expected. Whether the lack of correlation between age and whole nerve responses to ATP reflects a differential effect of ageing on separate nociceptor populations (serosal or non-serosal), or the contribution of another ATP sensitive afferent fibre population, that is unaffected by ageing, requires further research. Indeed, studies in mice have provided evidence for afferent subtypes stimulated by capsaicin and $\mathrm{P} 2 \mathrm{X}_{2 / 3}$ agonist activation (alpha, betamethylene ATP), and afferents only stimulated by either capsaicin or alpha, betamethylene ATP [4].

In contrast to the multiunit response, we found no effect of age on the response of single units discriminated from the multiunit recordings to capsaicin (or bradykinin, ATP and baseline activity). This would suggest that the reduced multiunit response to capsaicin (and trend for bradykinin) with age is most likely driven by a loss of innervation in the human colon with age, resulting in a reduced multiunit response to capsaicin, as opposed to the reduced ability of individual nociceptors to respond to noxious stimuli. The finding that the ability of individual human nociceptors to 
transduce noxious chemical stimuli is preserved with age is consistent with our previous report that the responses to bradykinin or ATP are unchanged with age in single unit recordings of human serosal nociceptors[22].

Finally, comparison of the data by patient gender or sex of the animal from which tissue was obtained did not reveal any marked differences in response, although a more comprehensive study examining the influence of gender is needed to substantiate these observations.

Our present study demonstrates that the ability of visceral nociceptors to signal noxious mechanical and inflammatory stimuli is significantly compromised with age, in mice and human tissue, consistent with clinical observations of reduced pain perception to appendicitis, pancreatitis and cholecystitis in the elderly[12; 21]. Data from human tissue suggests that this phenomenon is largely driven by a loss of spinal afferent innervation, however findings from mouse tissue suggest a reduced capacity to transduce inflammatory mediators may also play an important role. The mechanisms contributing to this loss of innervation and impaired capacity to transduce noxious stimuli was not investigated in this study, and future studies are needed to understand if these are mediated for example by changes in ion channel and receptor expression.

Furthermore, our data provides support to the hypothesis that age related changes in our ability to detect high threshold distension of the bowel may facilitate damage to the bowel, and contribute to the pathophysiology of diverticular disease, the prevalence of which increases significantly with advanced age[12; 31]. Additionally, the colorectum is also innervated by another population of spinal afferents, which project to the spinal cord via the pelvic nerve. Pelvic afferents are also implicated in colorectal pain and defecation, and future studies are needed to clarify the effects of ageing in this important visceral afferent population.

A final consideration is whether the age-related loss of visceral nociception seen in the present study, can be reversed or restored by therapeutic interventions, as part of a clinical strategy to improve well-being and gut health with age.

\section{Acknowledgements}

\section{Author Contributions}

Study design and concept (VCG, EJAA, VK, JRFH, AB, WJW, GJS, DCB); acquisition and analysis of data (VCG, EJAA, VK, JRFH, CM [human only], MT); interpretation of data and writing the manuscript (VCG, EJAA, VK, JRFH, CM, MT, 
AB, CHK, LAB, WJW, GJS, DCB). CM is funded by the Dr Hadwen Trust and did not participate in experiments involving animals, or cells or tissues from animals or from human embryos. All authors approved the final version of the manuscript.

\section{Funding}

This work was supported by an unrestricted educational grant from Neusentis (VCG), Bowel and Cancer Research (MT), The Dr Hadwen Trust for Human Research (CM).

\section{Conflicts of Interests}

Wendy Winchester and James Hockley were employees of Neusentis (Pfizer) at the time some studies were performed. Wendy Winchester is currently employed by Takeda Pharmaceuticals. David Bulmer holds shares in GlaxoSmithKline 


\section{REFERENCES}

[1] Bhutto A, Morley JE. The clinical significance of gastrointestinal changes with aging. Curr Opin Clin Nutr Metab Care 2008;11(5):651-660.

[2] Bitar K, Greenwood-Van Meerveld B, Saad R, Wiley JW. Aging and gastrointestinal neuromuscular function: insights from within and outside the gut. Neurogastroenterol Motil 2011;23(6):490-501.

[3] Booth CE, Kirkup AJ, Hicks GA, Humphrey PP, Grundy D. Somatostatin sst(2) receptor-mediated inhibition of mesenteric afferent nerves of the jejunum in the anesthetized rat. Gastroenterology 2001;121(2):358-369.

[4] Brierley SM, Carter R, Jones W, 3rd, Xu L, Robinson DR, Hicks GA, Gebhart GF, Blackshaw LA. Differential chemosensory function and receptor expression of splanchnic and pelvic colonic afferents in mice. J Physiol 2005;567(Pt 1):267-281.

[5] Brierley SM, Jones RC, 3rd, Gebhart GF, Blackshaw LA. Splanchnic and pelvic mechanosensory afferents signal different qualities of colonic stimuli in mice. Gastroenterology 2004;127(1):166-178.

[6] Brierley SM, Jones RC, 3rd, Xu L, Gebhart GF, Blackshaw LA. Activation of splanchnic and pelvic colonic afferents by bradykinin in mice. Neurogastroenterol Motil 2005;17(6):854-862.

[7] Brierley SM, Page AJ, Hughes PA, Adam B, Liebregts T, Cooper NJ, Holtmann G, Liedtke W, Blackshaw LA. Selective role for TRPV4 ion channels in visceral sensory pathways. Gastroenterology 2008;134(7):2059-2069.

[8] Choung RS, Locke GR, 3rd, Schleck CD, Zinsmeister AR, Talley NJ. The effects of ageing on the onset and disappearance of unexplained abdominal pain: a population-based study. Aliment Pharmacol Ther 2014;39(2):217-225.

[9] Firth M, Prather CM. Gastrointestinal motility problems in the elderly patient. Gastroenterology 2002;122(6):1688-1700.

[10] Greenwald DA. Aging, the gastrointestinal tract, and risk of acid-related disease. The American journal of medicine 2004;117 Suppl 5A:8S-13S.

[11] Gururatsakul M, Holloway RH, Adam B, Liebregts T, Talley NJ, Holtmann GJ. The ageing gut: diminished symptom response to a standardized nutrient stimulus. Neurogastroenterol Motil 2010;22(3):246-e277.

[12] Hall KE. Aging and neural control of the GI tract. II. Neural control of the aging gut: can an old dog learn new tricks? Am J Physiol Gastrointest Liver Physiol 2002;283(4):G827-832.

[13] Hockley JR, Boundouki G, Cibert-Goton V, McGuire C, Yip PK, Chan C, Tranter M, Wood JN, Nassar MA, Blackshaw LA, Aziz Q, Michael GJ, Baker MD, Winchester WJ, Knowles CH, Bulmer DC. Multiple roles for NaV1.9 in the activation of visceral afferents by noxious inflammatory, mechanical, and human disease-derived stimuli. Pain 2014;155(10):1962-1975.

[14] Hockley JR, Gonzalez-Cano R, McMurray S, Tejada-Giraldez MA, McGuire C, Torres A, Wilbrey AL, Cibert-Goton V, Nieto FR, Pitcher T, Knowles CH, Baeyens JM, Wood JN, Winchester WJ, Bulmer DC, Cendan CM, McMurray G. Visceral and somatic pain modalities reveal $\mathrm{NaV}$ 1.7-independent visceral nociceptive pathways. J Physiol 2017;595(8):2661-2679.

[15] Hockley JR, Tranter MM, McGuire C, Boundouki G, Cibert-Goton V, Thaha MA, Blackshaw LA, Michael GJ, Baker MD, Knowles CH, Winchester WJ, Bulmer DC. P2Y Receptors Sensitize Mouse and Human Colonic Nociceptors. J Neurosci 2016;36(8):2364-2376. 
[16] Hughes PA, Brierley SM, Blackshaw LA. Post-inflammatory modification of colonic afferent mechanosensitivity. Clin Exp Pharmacol Physiol 2009;36(10):1034-1040.

[17] Hughes PA, Brierley SM, Martin CM, Brookes SJ, Linden DR, Blackshaw LA. Post-inflammatory colonic afferent sensitisation: different subtypes, different pathways and different time courses. Gut 2009;58(10):13331341.

[18] Keating C, Nocchi L, Yu Y, Donovan J, Grundy D. Ageing and gastrointestinal sensory function: altered colonic mechanosensory and chemosensory function in the aged mouse. J Physiol 2016;594(16):4549-4564.

[19] Lagier E, Delvaux M, Vellas B, Fioramonti J, Bueno L, Albarede JL, Frexinos J. Influence of age on rectal tone and sensitivity to distension in healthy subjects. Neurogastroenterol Motil 1999;11(2):101-107.

[20] Lasch H, Castell DO, Castell JA. Evidence for diminished visceral pain with aging: studies using graded intraesophageal balloon distension. Am J Physiol 1997;272(1 Pt 1):G1-3.

[21] Lyon C, Clark DC. Diagnosis of acute abdominal pain in older patients. American family physician 2006;74(9):1537-1544.

[22] McGuire C, Boundouki G, Hockley JR, Reed D, Cibert-Goton V, Peiris M, Kung V, Broad J, Aziz Q, Chan C, Ahmed S, Thaha MA, Sanger GJ, Blackshaw LA, Knowles CH, Bulmer DC. Ex vivo study of human visceral nociceptors. Gut 2016.

[23] Mohammed HA, Santer RM. Distribution and changes with age of calcitonin gene-related peptide- and substance P-immunoreactive nerves of the rat urinary bladder and lumbosacral sensory neurons. Eur J Morphol 2002;40(5):293-301.

[24] Phillips RJ, Pairitz JC, Powley TL. Age-related neuronal loss in the submucosal plexus of the colon of Fischer 344 rats. Neurobiol Aging 2007;28(7):1124-1137.

[25] Phillips RJ, Powley TL. Innervation of the gastrointestinal tract: patterns of aging. Auton Neurosci 2007;136(1-2):1-19.

[26] Phillips RJ, Walter GC, Powley TL. Age-related changes in vagal afferents innervating the gastrointestinal tract. Auton Neurosci 2010;153(1-2):9098.

[27] Ranson RN, Saffrey MJ. Neurogenic mechanisms in bladder and bowel ageing. Biogerontology 2015;16(2):265-284.

[28] Rao SS, Go JT. Update on the management of constipation in the elderly: new treatment options. Clin Interv Aging 2010;5:163-171.

[29] Saffrey MJ. Cellular changes in the enteric nervous system during ageing. Dev Biol 2013;382(1):344-355.

[30] Spencer NJ, Kyloh M, Duffield M. Identification of different types of spinal afferent nerve endings that encode noxious and innocuous stimuli in the large intestine using a novel anterograde tracing technique. PloS one 2014;9(11):e112466.

[31] Spiller RC. Changing views on diverticular disease: impact of aging, obesity, diet, and microbiota. Neurogastroenterol Motil 2015;27(3):305-312.

[32] Wiskur B, Greenwood-Van Meerveld B. The aging colon: the role of enteric neurodegeneration in constipation. Curr Gastroenterol Rep 2010;12(6):507-512. 
Fig. 1 Intestinal afferent responses to supernatant from inflamed human appendix, and bradykinin, are greatly reduced with age. (A) Raw trace showing ongoing nerve activity expressed as a mean frequency and exerts of the neurogram (highlighted by dotted lines) from sections of trace showing multiunit nerve activity before and after bath perfusion with respective supernatants (marked on trace by black bar); illustrating (i) the minimal response to supernatant generated from non-inflamed appendix (male, age 57) and (ii) the increase in nerve discharge to supernatant generated from inflamed appendix (female, age 26) in tissue from a young female mouse ( 3 month); and (iii) the lack of response to bath perfusion with supernatant generated from inflamed appendix (female, age 26) in tissue from an old female mouse (24 month). (B) (i) Bar chart showing the mean \pm SEM increase in mesenteric nerve activity following application of supernatants generated from non-inflamed ( $\mathrm{N}=5$ nerves in $\mathrm{n}=3$ mice 1 female, 2 male; open bar) and inflamed (filled bar) appendix in tissue from young ( $\mathrm{N}=8$ nerves in $\mathrm{n}=6$ mice ( 3 female, 3 male) or old $(\mathrm{N}=8$ nerves in $\mathrm{n}=6$ mice ( 3 female, 3 male) animals. (ii) Dot plots showing the matched afferent response to $n=8$ individual inflamed supernatants tested in tissue from young and old mice $(N=8$ nerves, from $n=6$ mice per age group ( 3 female, 3 male per group)). (iii) Dot plots illustrating the afferent response in individual nerves to non-inflamed and inflamed supernatants characterised by the sex of the patient from which appendix tissue was obtained (data from female patients is represented by blue circles and male patients by red squares). (C) (i) Bar chart showing the mean \pm SEM concentration of cytokines in supernatants generated from non-inflamed (open bar) and inflamed (filled bar) appendix. (ii) Dot plots illustrating the cytokine concentrations from individual non-inflamed and inflamed supernatants characterised by the sex of the patient from which appendix tissue was obtained (data from female patients is represented by blue circles and male patients by red squares). (D) Raw trace showing ongoing nerve activity expressed as a mean frequency (60s time base) and accompanying neurogram in tissue from young and old female mice, before and after the application of bradykinin to the tissue bath (time of application indicated by arrow). (E) Bar chart showing the mean \pm SEM increase in mesenteric nerve activity elicited by bradykinin application in tissue from young $(\mathrm{N}=10$ nerves in $\mathrm{n}=5$ mice, open bar) or old ( $\mathrm{N}=10$ nerves in $\mathrm{n}=8$ mice, filled bar) female animals. $\left({ }^{*} p<0.05,{ }^{* *} p<0.01,{ }^{* * *} p<0.005\right.$ unpaired Student's t-test). 
Fig. 2 Substantial loss of sensory innervation illustrated by CGRP positive fibres in whole mount preparation of terminal ileum from old compared with young mice. (A) Images showing full thickness tissue staining for CGRP positive afferent fibres from young (left panels) and old (right panels) female mice highlighting: ( $\mathrm{i}$ - ii) loss of perivascular nerve fibers; (iii - iv) loss of CGRP positive fibers reaching the outer surface of the intestine; and loss of fibres within the $(v-v i)$ serosa. Scale bar is 25 $\mu \mathrm{m}$. (B) Bar chart showing the change in the density of CGRP-like immunoreactivity (fluorescent intensity per image, expressed as mean \pm SEM values) in the small intestine, highlighting the significant reduction with age $\left({ }^{*} p<0.05\right.$, unpaired Student's t-test). 
Fig. 3 Sensory innervation of the colon by splanchnic afferents is markedly reduced with age. Substantial reduction of thoracolumbar (T13-L1) neurones retrogradely labelled following tracer injection (fast blue) in to the wall of the descending colon was seen in old mice. (A) images taken from sections of thoracolumbar DRGs illustrating FB positive neurones (white arrows) from (i) young (3 month) and (ii) old (24 month) female mice. Scale bar is $50 \mu \mathrm{m}$. (B) Bar charts showing the significant reduction in DRG cellularity with age (i; expressed as mean \pm SEM cell counts per section), and the significant reduction in DRGs neurones retrogradely labelled by colonic tracer injection (ii, shown by the number of fast blue positive neurones expressed as a \% of total cell counts per section) in tissue from young (open bars) compared with old (filled bar) female mice. In addition, (C) electrophysiological studies of lumbar splanchnic nerve activity in flat sheet colonic preparations demonstrated a significant reduction in the number of mechanosensitive (systematic $0.6 \mathrm{~g}$ VFH probing) receptive fields (RFs) found per lumbar splanchnic nerve (LSN) bundle recorded, in (i) mesenteric and (ii) serosal layers of the colon in tissue from old (filled bar) vs young (open bar) female mice (data expressed as mean \pm SEM values) ${ }^{* * *} p<0.005$; unpaired Student's t-test). 
Fig. 4 The multiunit colonic nerve response to luminal distension ( 0 to $80 \mathrm{mmHg}$ ) is blunted at noxious distending pressures $(40-80 \mathrm{mmHg})$, in tissue from old vs young mice. (A) Rate histograms of ongoing neuronal activity and respective luminal pressure trace illustrating the difference in the lumbar splanchnic nerve response and change in tissue compliance to ramp distension of the colon in tissue from a 3 month (i) compared with a 24 month (ii) old female mouse. Line graph showing (B) the significant decrease in the afferent response in tissue from old $(N=7$ nerves in $n=7$ mice ( 4 female, 3 male); filled circles) compared with young ( $N=7$ nerves in $n=7$ mice (4 female, 3 male); open circles) mice (data expressed as mean \pm SEM values, $p<0.05$ 2-way ANOVA). (C) Line graph showing the significant increase in tissue compliance to ramp distension of the colon, in tissue from old ( $n=7$ mice (4 female, 3 male); filled circles) compared with young ( $n=7$ mice (4 female, 3 male); open circles) mice (data expressed as mean \pm SEM values, $p<0.05$ 2-way ANOVA). Afferent response to ramp distension was significantly reduced at noxious $(40-80 \mathrm{mmHg})$ distending pressures, while an increase in compliance was observed at all distending pressures (Bonferroni's post hoc test, ${ }^{* *} p<0.01,{ }^{* *} p<0.005$ ). 
Fig. 5 Mechanosensitivity of individual colonic afferents to probing of their serosal receptive fields with VFH is unchanged with age suggesting that a loss of innervation may be responsible for the blunted multiunit response to high threshold distension. (A) Neurogram and instantaneous frequency plots illustrating the magnitude of the afferent response to 3 successive probes with a $0.6 \mathrm{~g}$ (left traces) and a $1.0 \mathrm{~g} \mathrm{VFH}$ (right traces) of the serosal receptive field of colonic afferent fibres in tissue from 3 month and 24 month old female mice. (B) Bar graphs showing the comparable response to probing with (i) 0.6 and (ii) $1.0 \mathrm{~g} \mathrm{VFHs} \mathrm{in} \mathrm{tissue} \mathrm{from} \mathrm{old} \mathrm{(} \mathrm{N}=24$ and $\mathrm{N}=24$ fibres respectively from $n=10$ mice filled bar) and young $(N=21$ and $N=16$ fibres respectively from $n=12$ mice; open bar) female mice (data expressed as mean \pm SEM values, $p>0.05$, unpaired Student's t-test). 
Fig. 6 By contrast the chemosensitivity of individual colonic afferents to algogenic inflammatory mediators was markedly impaired with age. (A) Raw traces (top panels rate histogram and bottom panels respective neurogram) illustrating the colonic afferent response to the application of BK $1 \mu \mathrm{M}$ (black arrows); in tissue from (i) 3 month and (ii) 24 month old female mice. (B) Bar chart showing the mean \pm SEM change in colonic afferent firing following application of $300 \mathrm{nM}$, and $1 \mu \mathrm{M}$ bradykinin in tissue from young ( $300 \mathrm{nM} ; \mathrm{N}=5$ fibres from $n=4$ mice; $1 \mu \mathrm{M} \mathrm{N}=5$ fibres from $n=4$ mice; open bar) and old (300nM; $N=5$ fibres from $n=4$ mice; $1 \mu \mathrm{M} \mathrm{N}=5$ fibres from $n=3$ mice; filled bar) female mice ( ${ }^{*} p<0.05$, unpaired Student's t-test). (C) Raw traces (top panels rate histogram and bottom panels respective neurogram) highlighting the colonic afferent response to application of an experimental inflammatory soup in tissue from (i) 3 month and (ii) 24 month old female mice. (D) Bar chart showing the mean \pm SEM change in colonic afferent firing following application of an experimental inflammatory soup in tissue from young ( $N=10$ fibres from $n=5$ mice; open bar) and old ( $N=7$ fibres from $n=3$ mice; filled bar) female mice ( ${ }^{*} p<0.05$ unpaired Student's $t$ test). 
Fig. 7 Individual colonic afferent responses to appendicitis supernatant was also greatly impaired in tissue from old mice. (A) Raw traces (top panels rate histogram and bottom panels respective neurogram) illustrating the colonic afferent response to the application of an inflamed appendicitis supernatant (female, age 26) (black arrows) in tissue from (i) 3 month and (ii) 24 months old female mice. (B) Bar chart showing the mean \pm SEM change in colonic afferent activity to inflamed appendicitis supernatant ( $\mathrm{n}=6$ individual supernatants tested) in tissue from young ( $\mathrm{N}=7$ fibres from $n=6$ mice; open bar) vs old ( $N=5$ fibres from $n=4$ mice; filled bar) female mice ( ${ }^{*} p<0.005$ unpaired Student's t-test). (ii) Dot plots showing the matched afferent response to $n=4$ individual inflamed appendicitis supernatants tested on $N=6$ fibres from $n=5$ young female mice and $N=4$ fibres from $n=3$ old female mice. Note not all supernatants were tested in tissue from young and old mice. One supernatant was only tested in tissue from young mice and one supernatant was only tested in tissue from old mice. (iii) Dot plots illustrating the afferent response in individual nerves to inflamed appendicitis supernatants characterised by the sex of the patient from which appendix tissue was obtained (data from female patients is represented by blue circles and male patients by red squares). (C) In addition, the application of inflamed appendicitis supernatant (female, age 26) sensitised the mechanosensitivity of individual colonic afferents. Neurogram and instantaneous frequency plots illustrating the increased afferent response to VFH probing $(0.6 \mathrm{~g})$ of the receptive field of individual colonic afferents before (left trace) compared with after (right trace) application of appendicitis supernatants in tissue from (i) 3 month and (ii) 24 month old female mice. (D) (i) Bar charts showing the mean \pm SEM response to VFH probing before and after application of appendicitis supernatant in tissue from young ( $N=4$ fibres from $n=3$ mice) and old ( $N=4$ fibres from $n=3$ mice) female mice ( ${ }^{*} p<$ 0.05; paired one-way Student's t-test). (ii) Dot plots showing the matched change in afferent response to VFH probing before and after application of $n=4$ individual appendicitis supernatants tested in tissue from young and old female mice. 
Fig. 8 Translational studies confirmed that human colonic nociceptor signalling is also impaired with age. (A) Raw traces (top panels rate histogram and bottom panels respective neurogram) illustrating the multiunit mesenteric nerve response to capsaicin in tissue from (i) a younger (<60 years old) patient (female, age 48), and (ii) a older ( $>70$ years old) patient (male, age 79 ). Scatter plots and linear regression showing, $(B)$ the significant negative correlation $(p<0.05)$ between the response to

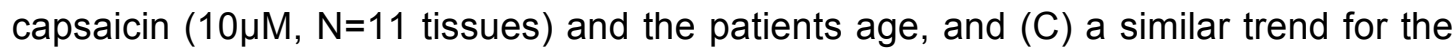
response to bradykinin $(10 \mu \mathrm{M}, \mathrm{N}=10$ tissues). By contrast no correlation was found in (D) the multiunit mesenteric nerve response to ATP $(10 \mathrm{mM}, \mathrm{N}=10$ tissues), or (E) baseline ongoing discharge ( $N=19$ tissues) suggesting that the response was selective for nociceptors. Data was statistically analysed using Spearman's correlations significance set at ${ }^{*} p<0.05$. Data from female patients is represented by blue circles and data from male patients is represented by red squares. 
Fig. 9 By contrast no correlation was found between a patients' age and the response to capsaicin in single unit colonic afferent fibre activity discriminated from the multiunit recordings shown in Figure 8. (A-D) Scatter plots and linear regression showing the lack of correlation between the patient's age and the response of discriminated single units to $(A)$ capsaicin $(10 \mu \mathrm{M}, \mathrm{n}=5$ units), (B) bradykinin $(10 \mu \mathrm{M}$, $n=7$ units). (C) ATP (10mM, $n=7$ units) and (D) baseline ongoing discharge $(n=12$ units). Data was statistically analysed using Spearman's correlations significance set at ${ }^{*} p<0.05$. Data from female patients is represented by blue circles and data from male patients is represented by red squares. 


\section{Table 1}

\begin{tabular}{|c|c|c|c|c|c|c|c|}
\hline \multirow{2}{*}{$\begin{array}{c}\text { Patient } \\
\text { no. }\end{array}$} & \multirow[b]{2}{*}{ Disease } & \multirow[b]{2}{*}{ Procedure } & \multirow[b]{2}{*}{ Age } & \multirow[b]{2}{*}{ Gender } & \multicolumn{3}{|c|}{ Single } \\
\hline & & & & & Whole nerve & fibre & Cytokines \\
\hline 1 & Appendicitis & Appendectomy & 26 & $\mathrm{~F}$ & $\checkmark$ & $\checkmark$ & $\checkmark$ \\
\hline 2 & Appendicitis & Appendectomy & 48 & M & $\checkmark$ & $\checkmark$ & $\checkmark$ \\
\hline 3 & Appendicitis & Appendectomy & 23 & $\mathrm{~F}$ & $\checkmark$ & $\checkmark$ & $\checkmark$ \\
\hline 4 & Appendicitis & Appendectomy & 26 & M & $\checkmark$ & $\checkmark$ & $\checkmark$ \\
\hline 5 & Appendicitis & Appendectomy & 51 & $\mathrm{~F}$ & $\checkmark$ & $\checkmark$ & $\checkmark$ \\
\hline 6 & Appendicitis & Appendectomy & 20 & $\mathrm{~F}$ & $\checkmark$ & $\checkmark$ & \\
\hline 7 & Appendicitis & Appendectomy & 19 & M & $\checkmark$ & & \\
\hline \multirow[t]{2}{*}{8} & Appendicitis & Appendectomy & 30 & $\mathrm{~F}$ & $\checkmark$ & & \\
\hline & & Mean age / M:F ratio & 30.4 & $1: 1.7$ & & & \\
\hline 9 & Cancer & Anterior resection & 50 & $\mathrm{~F}$ & & & $\checkmark$ \\
\hline 10 & Cancer & Right hemicolectomy & 53 & M & & & $\checkmark$ \\
\hline 13 & Cancer & laparotomy for retroperitoneal & 30 & $\mathrm{~F}$ & & & $\checkmark$ \\
\hline 11 & Cancer & Right hemicolectomy & 50 & $\mathrm{~F}$ & $\checkmark$ & & $\checkmark$ \\
\hline 12 & Cancer & Subtotal colectomy & 57 & M & $\checkmark$ & & $\checkmark$ \\
\hline 14 & Cancer & Right hemicolectomy & 72 & M & $\checkmark$ & & \\
\hline 15 & Cancer & Right hemicolectomy & 62 & $\mathrm{~F}$ & $\checkmark$ & & \\
\hline \multirow[t]{2}{*}{16} & Cancer & Subtotal colectomy & 62 & $\mathrm{~F}$ & $\checkmark$ & & \\
\hline & & Mean age / M:F ratio & 54.5 & $1: 1.7$ & & & \\
\hline
\end{tabular}

\section{Table 1}

Patient details (disease, procedures, age and gender), and experimental studies performed, with supernatants generated from respective appendix. 
Table 2

\begin{tabular}{|c|c|c|c|c|c|c|c|}
\hline $\begin{array}{c}\text { Patient } \\
\text { no. }\end{array}$ & $\begin{array}{c}\text { Disease / } \\
\text { Therapy }(\mathrm{R} / \mathrm{C} / \mathrm{N})\end{array}$ & Procedure & Specimen & Age & Gender & $\begin{array}{l}\text { Multi } \\
\text { unit }\end{array}$ & $\begin{array}{c}\text { Single } \\
\text { unit }\end{array}$ \\
\hline 1 & Cancer & Right hemicolectomy & Ascending colon & 24 & $\mathrm{M}$ & - & A \\
\hline 2 & Cancer / N & Anterior resection & Sigmoid Colon & 39 & M & A & - \\
\hline 3 & D.D. / N & Anterior resection & Sigmoid Colon & 47 & M & B & - \\
\hline 4 & Cancer / C & RPS (previous APER) & Caecum & 48 & $\mathrm{~F}$ & $\mathrm{CP}$ & - \\
\hline 5 & Cancer / C & Left hemicolectomy & Sigmoid Colon & 52 & M & $\mathrm{B} / \mathrm{CP}$ & $\mathrm{CP}$ \\
\hline 6 & Cancer / R, C & Anterior resection & Sigmoid Colon & 54 & M & $\mathrm{A} / \mathrm{B} / \mathrm{CP}$ & $\mathrm{A} / \mathrm{B} / \mathrm{CP}$ \\
\hline 7 & Cancer / C & Complete colectomy & Sigmoid Colon & 54 & $\mathrm{~F}$ & $\mathrm{~A} / \mathrm{CP}$ & $\mathrm{CP}$ \\
\hline 8 & Cancer / R, C & Anterior resection & Sigmoid Colon & 54 & M & B & B \\
\hline 9 & Cancer / N & Anterior resection & Sigmoid Colon & 60 & M & A & - \\
\hline 10 & Cancer / N & Anterior resection & Sigmoid Colon & 60 & M & $\mathrm{A} / \mathrm{B} / \mathrm{CP}$ & $\mathrm{A} / \mathrm{B}$ \\
\hline 11 & Cancer / R & Anterior resection & Sigmoid Colon & 64 & M & $\mathrm{A} / \mathrm{B} / \mathrm{CP}$ & $\mathrm{A} / \mathrm{B}$ \\
\hline 12 & D.D. / N & Anterior resection & Sigmoid Colon & 64 & M & A & A \\
\hline 13 & Cancer / N & Colectomy & Sigmoid Colon & 66 & M & B & B \\
\hline 14 & Cancer / N & Anterior resection & Sigmoid Colon & 71 & $\mathrm{~F}$ & B & B \\
\hline 15 & Cancer / N & Right hemicolectomy & Ascending colon & 72 & $\mathrm{~F}$ & $\mathrm{CP}$ & - \\
\hline 16 & Cancer / N & Left hemicolectomy & Sigmoid Colon & 72 & M & $\mathrm{A} / \mathrm{CP}$ & A \\
\hline 17 & Cancer / R & Anterior resection & Sigmoid Colon & 73 & M & $\mathrm{B} / \mathrm{CP}$ & - \\
\hline 18 & Cancer / N & Anterior resection & Sigmoid Colon & 78 & M & A & A \\
\hline 19 & \multirow{3}{*}{\multicolumn{3}{|c|}{$\begin{array}{c}\text { Ascending colon } \\
\text { Mean age / M:F ratio }\end{array}$}} & 78 & M & $\mathrm{CP}$ & $\mathrm{CP}$ \\
\hline \multirow[t]{2}{*}{20} & & & & 82 & M & \multirow[t]{2}{*}{$\mathrm{B} / \mathrm{CP}$} & \multirow[t]{2}{*}{$\mathrm{B} / \mathrm{CP}$} \\
\hline & & & & 63 & $3.75: 1$ & & \\
\hline
\end{tabular}

Abbreviations: R, Radiotherapy; C, Chemotherapy; N, No Chemo- or Radiotherapy; DD, Diverticular Disease; RPS Reconstructive pelvic surgery; APER, Abdominoperineal excision of rectum; A, adenosine triphosphate (ATP); B, bradykinin; CP, capsaicin.

Table 2

Patient details (disease, procedures, tissue region, age and gender), of tissues used from human colonic mesenteric nerve recordings. 
Figure 1

A
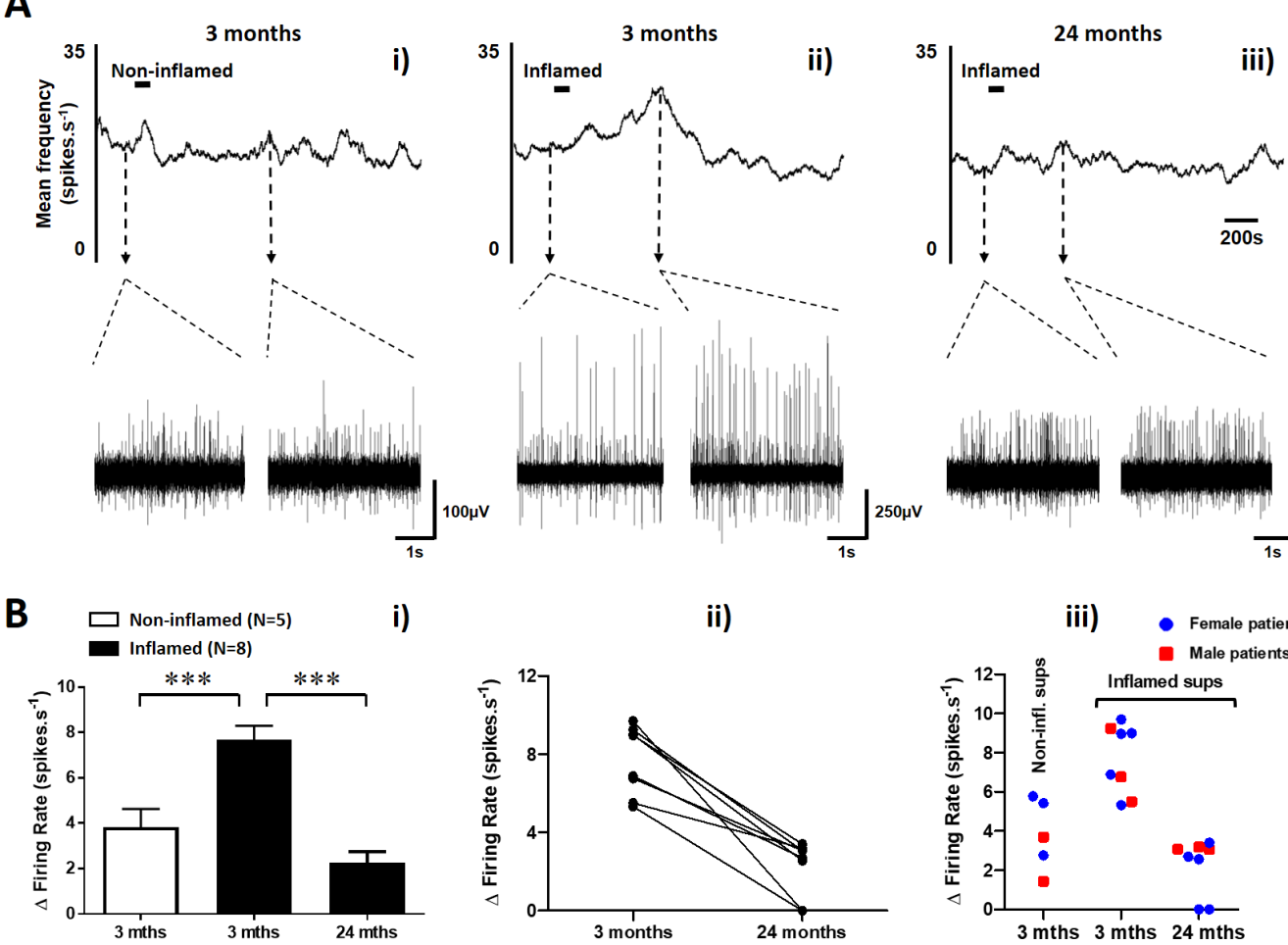

ii)
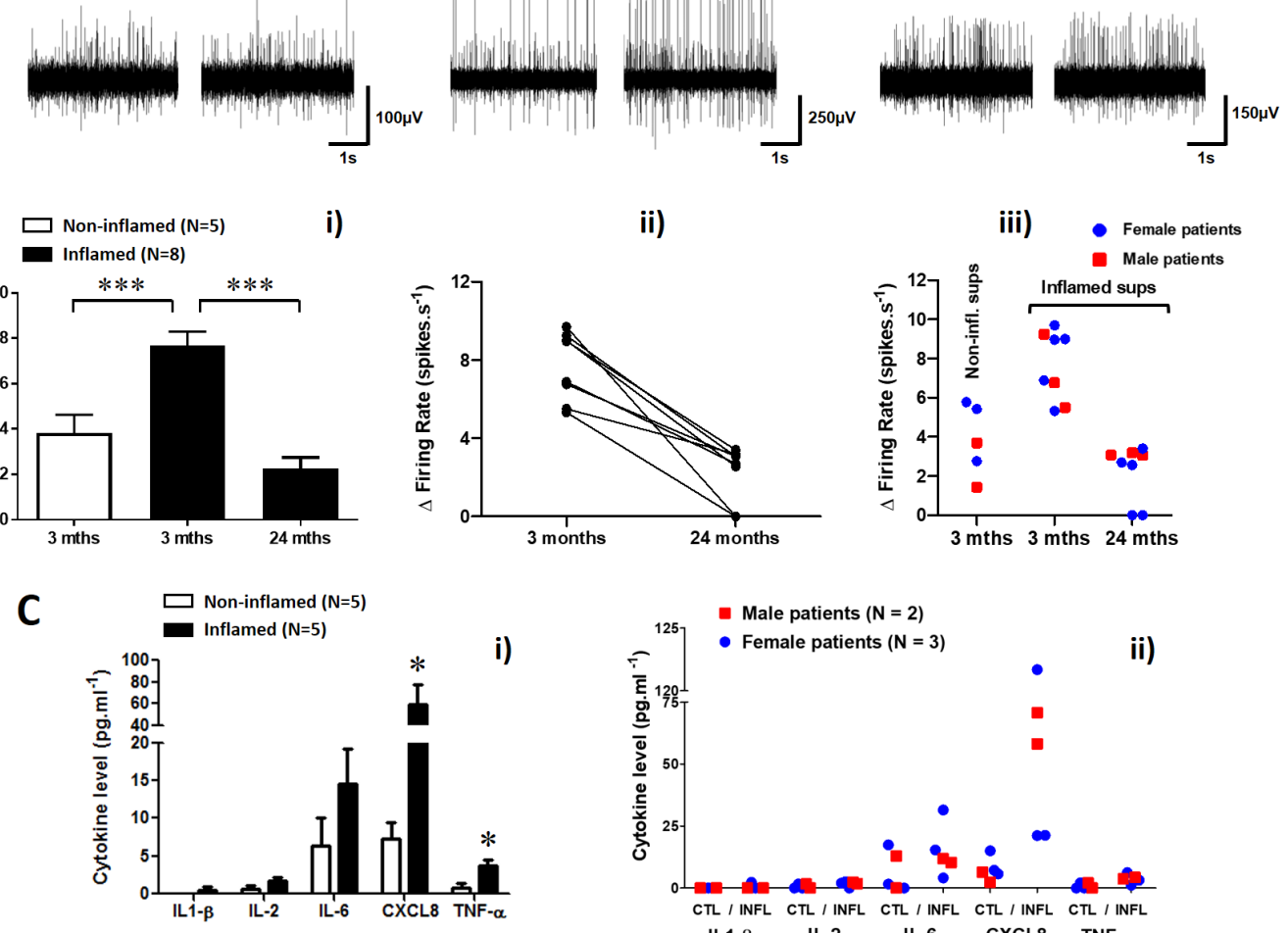

iii) Female patients

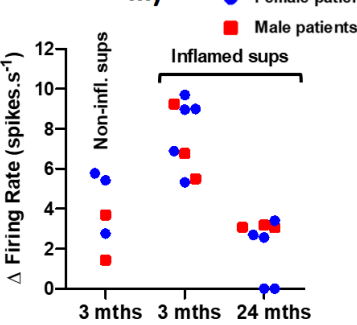

D

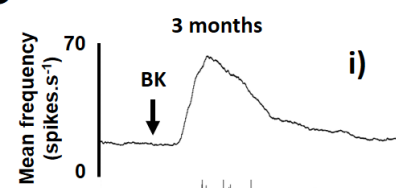

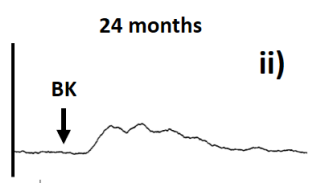

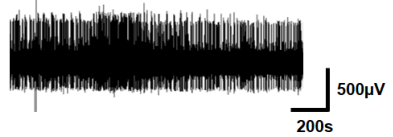

E

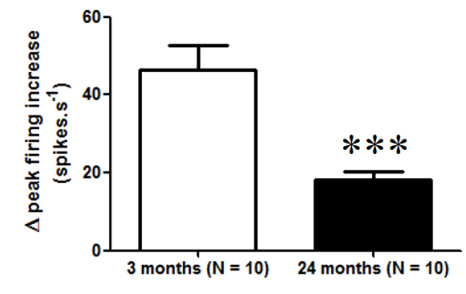


Figure 2

A
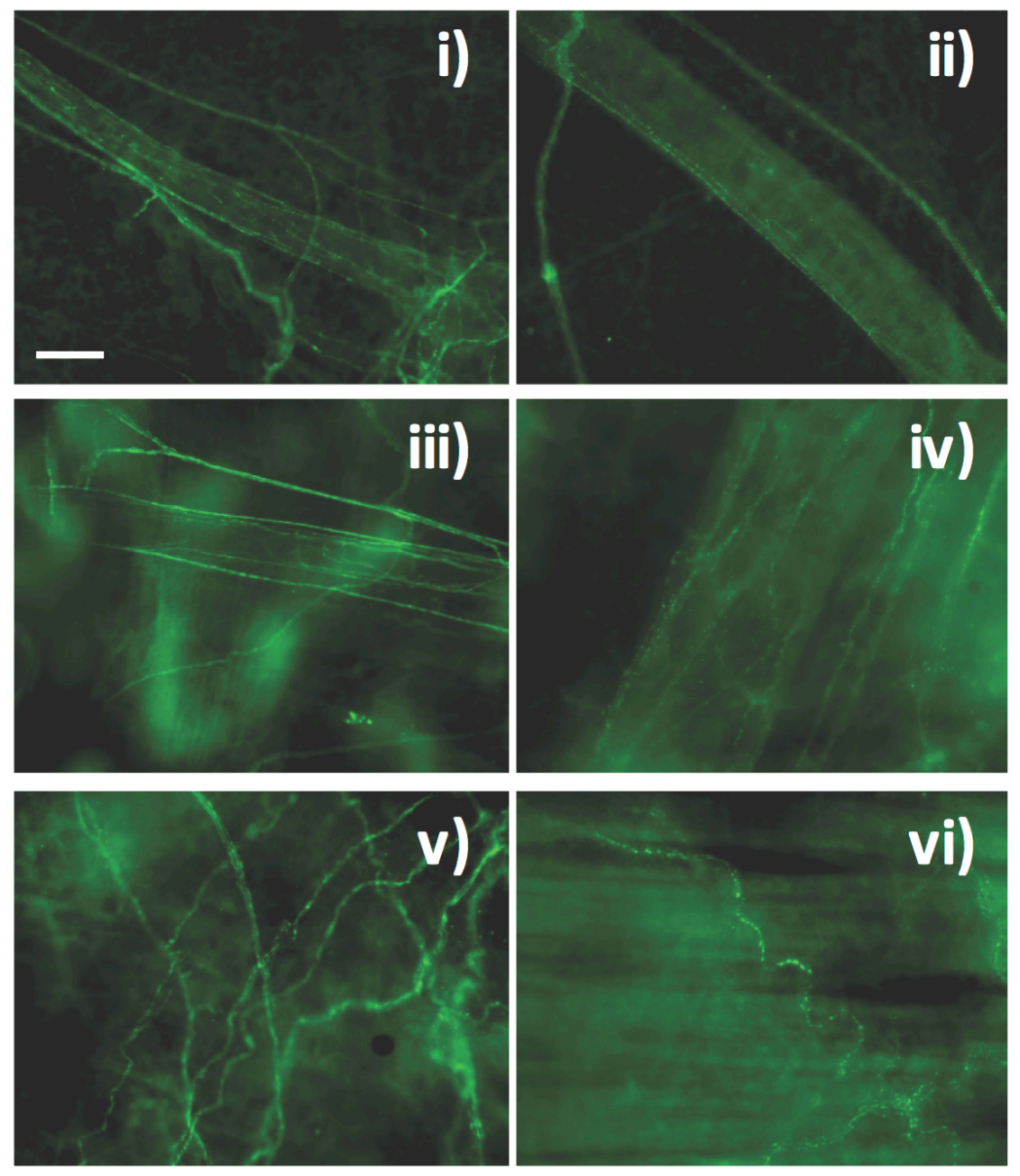

B

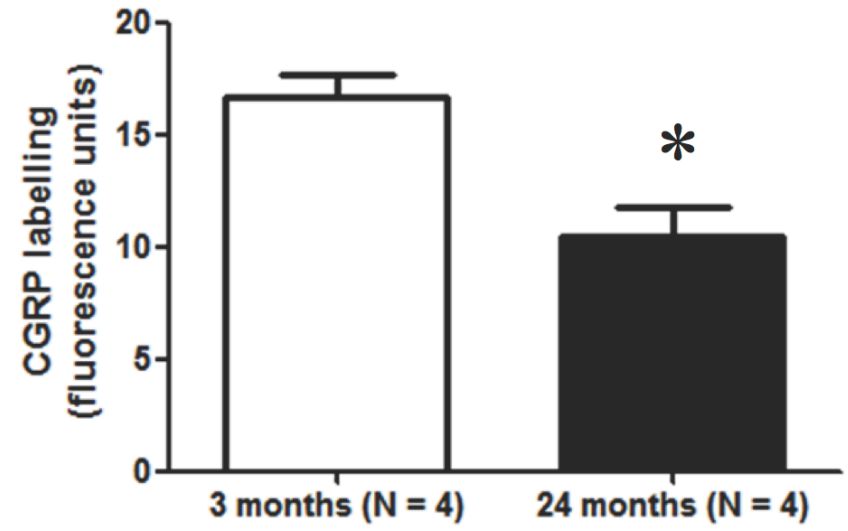


Figure 3

A

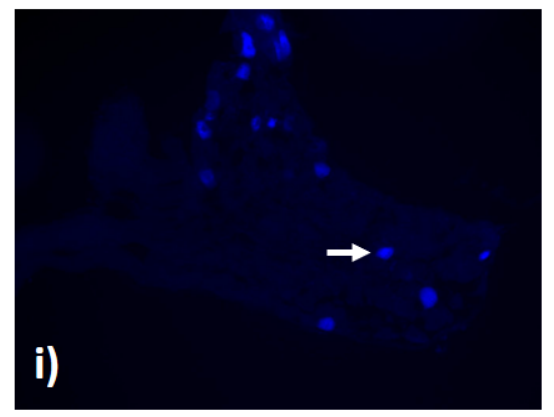

B
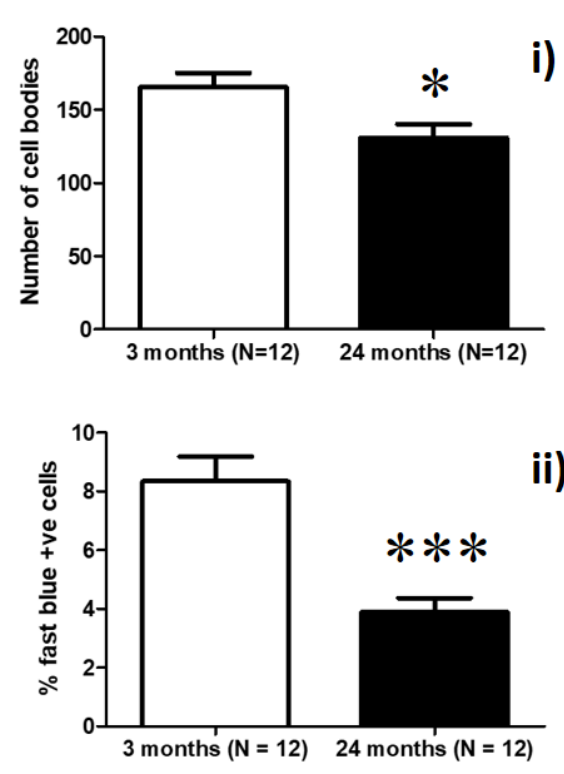
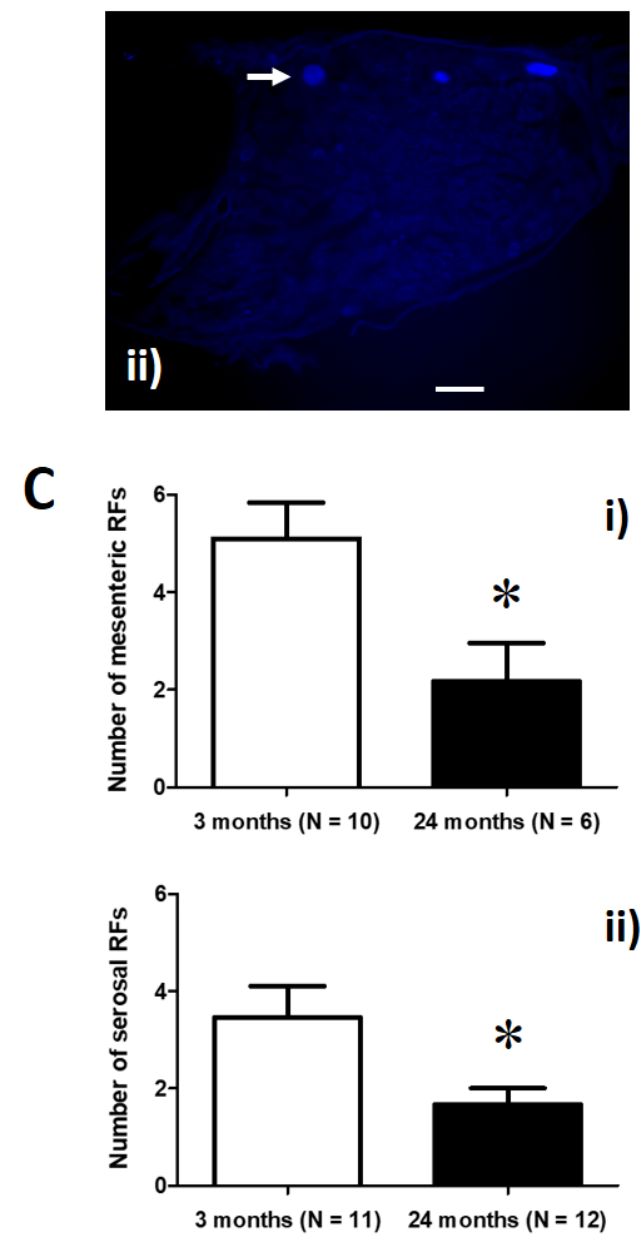
Figure 4

A
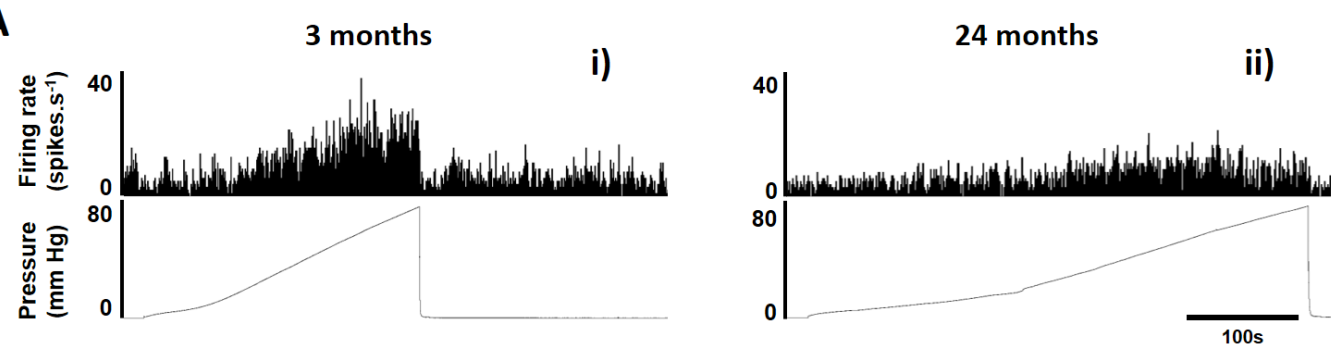

B

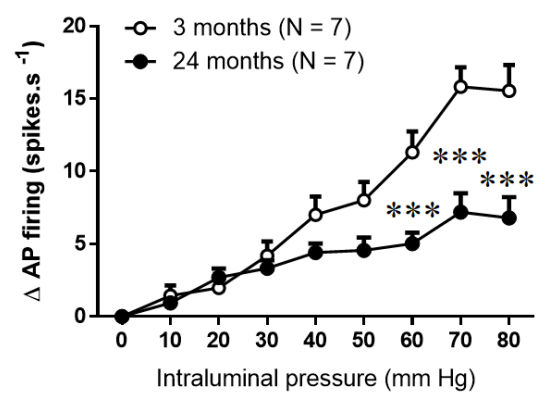

C

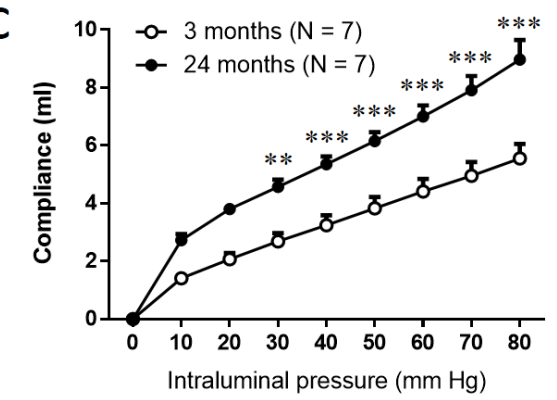


Figure 5

A
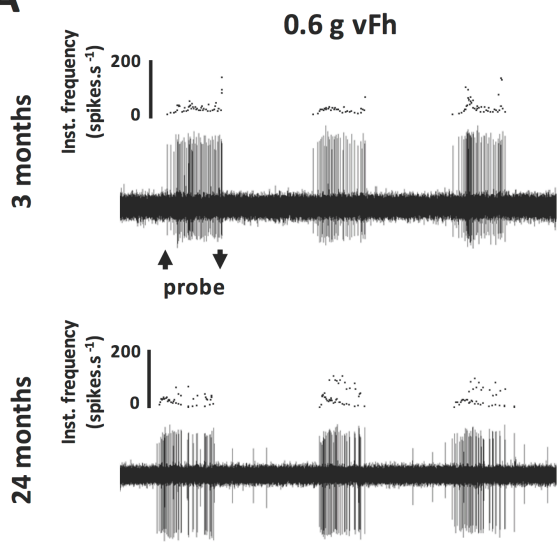

B

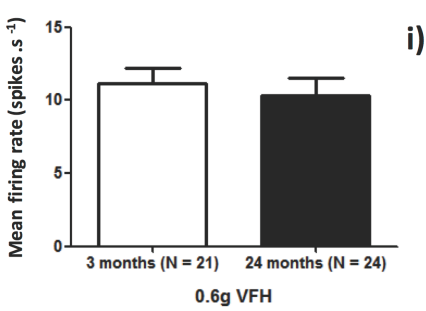

$1.0 \mathrm{~g} \mathrm{vFh}$
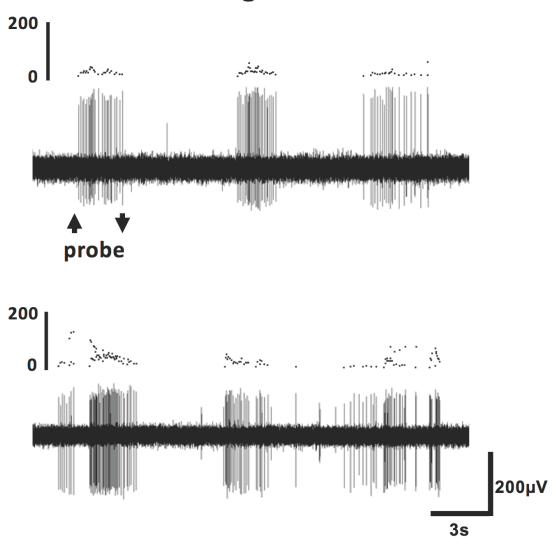

ii)

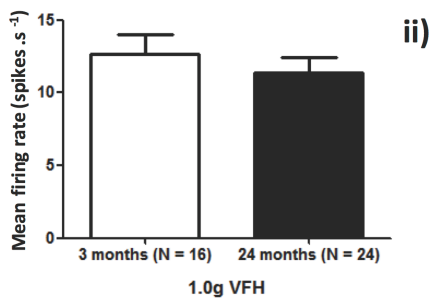


Figure 6

A

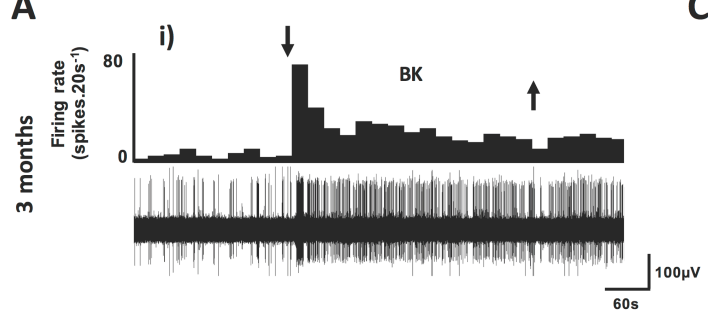

C
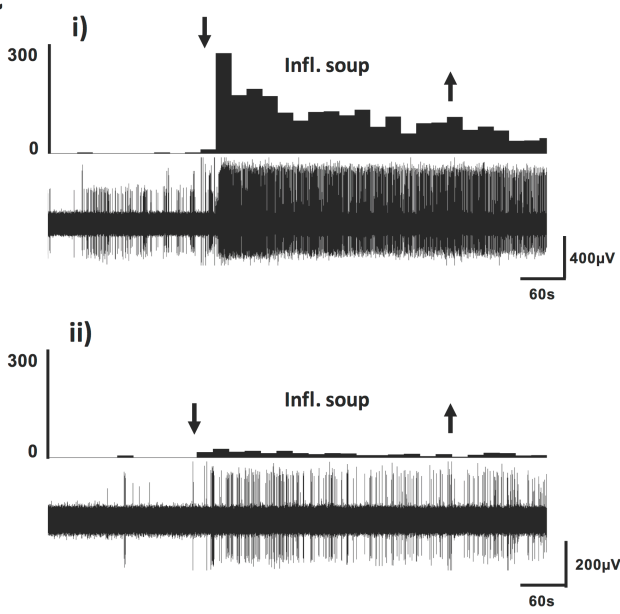

D

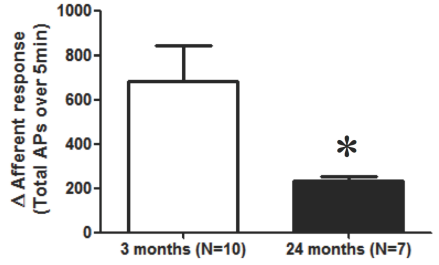


Figure 7
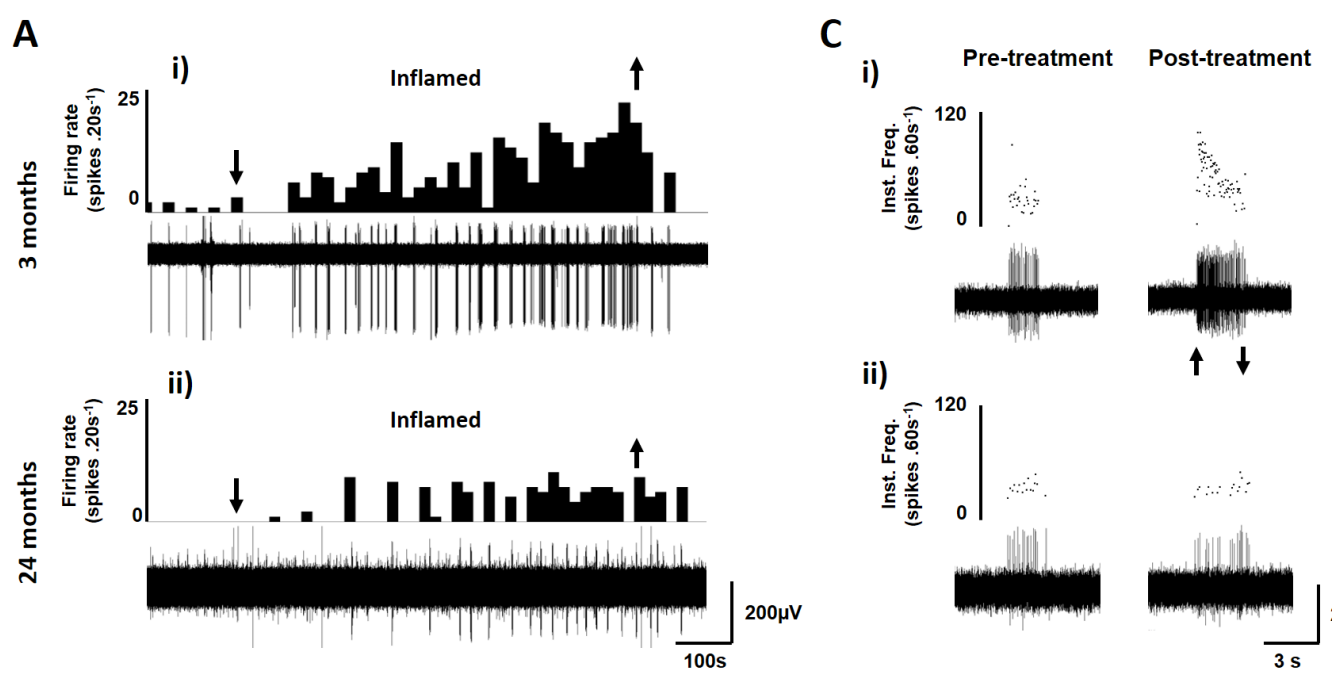

B

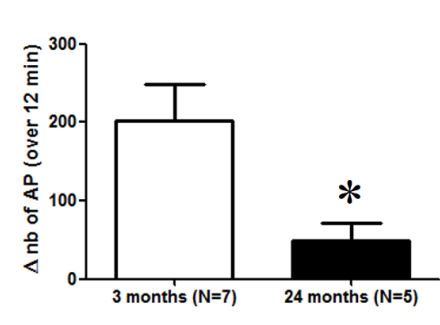

- Male patients

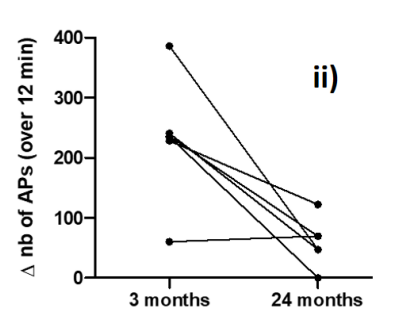

i)

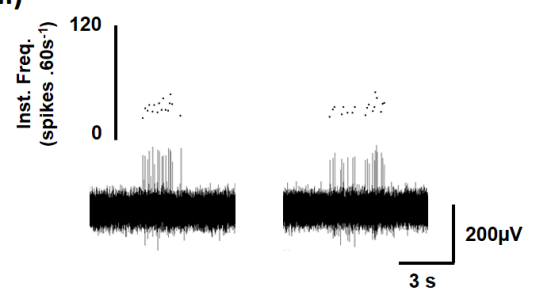

D
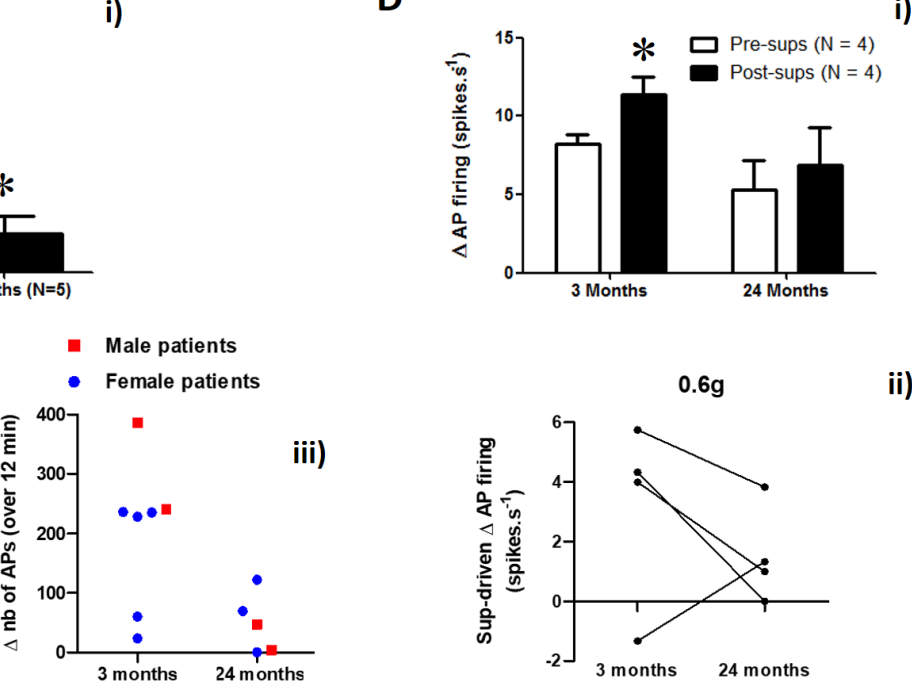

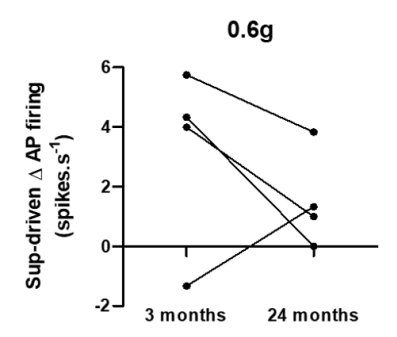


Figure 8
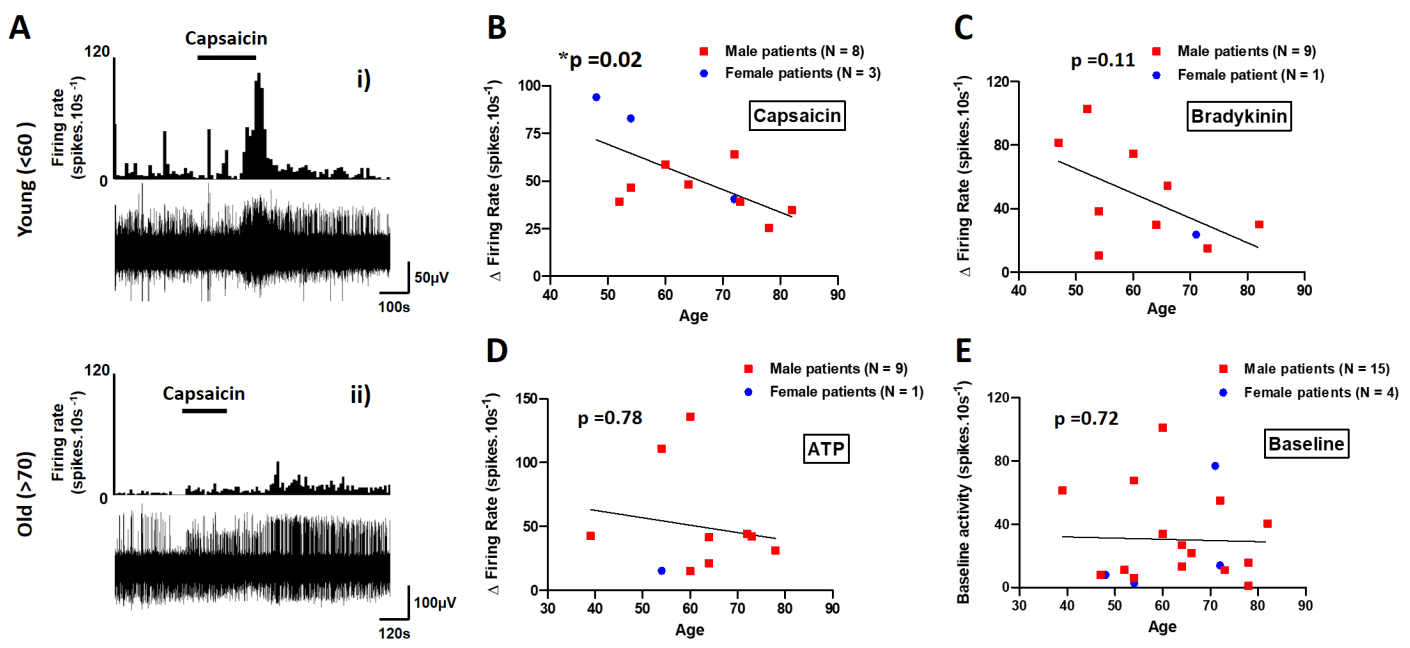
Figure 9

A

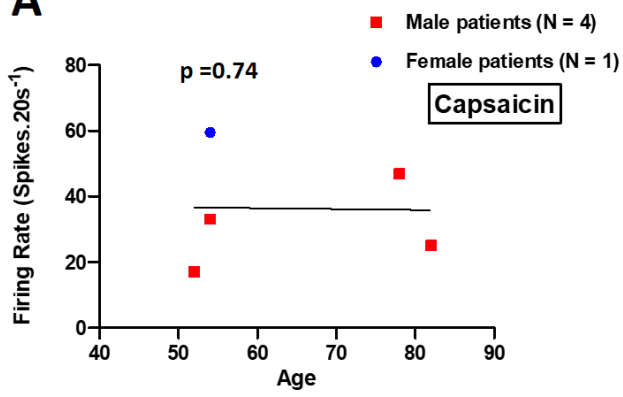

C

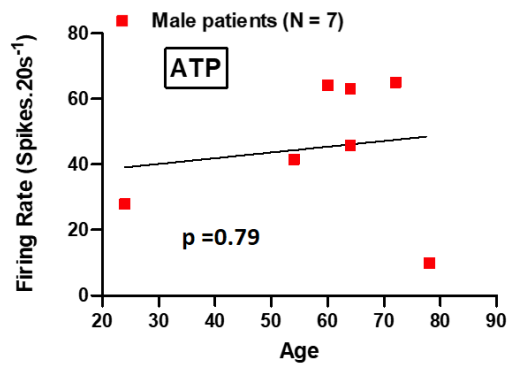

B

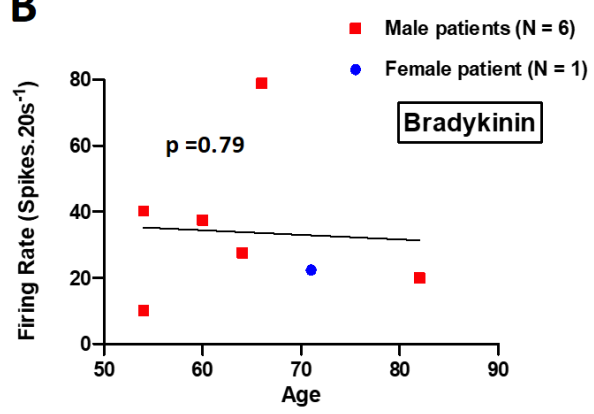

D

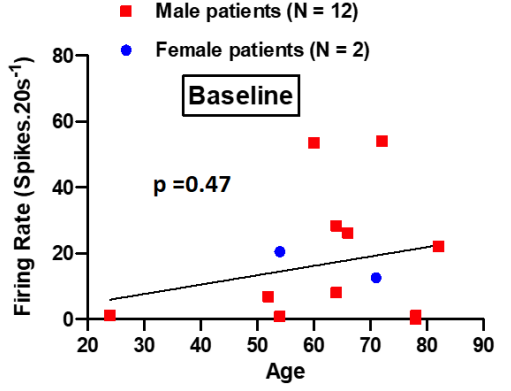




\section{SUPPLEMENTAL RESULTS}

\section{Supplemental Fig. 1}

The age and sex of the patient from which inflamed appendix were surgically resected had no effect on the magnitude of intestinal mesenteric nerve response to supernatants generated from respective inflamed appendix. (A) Scatter plot illustrating the increase in mesenteric nerve activity in tissue from young mice $(\mathrm{N}=8$ nerves, from $n=6$ mice, 3 female, 3 male) and the age and sex of the patient from which the inflamed appendix was obtained (data from female patients is represented by blue circles and male patients by red squares). Statistical analysis performed using Spearman's correlations; $p>0.05$.

Additionally, no difference was observed in the intestinal mesenteric nerve response to non-inflamed or inflamed appendix supernatants in young and old animals respectively based on the sex of the animal from which the tissue was obtained. (B) Dot plots illustrating the individual intestinal mesenteric nerve responses to the application of non-inflamed appendix supernatants $(\mathrm{N}=5$ nerves in $\mathrm{n}=3$ mice 1 female, 2 male) in young mice; and inflamed appendix supernatants in tissue from young ( $\mathrm{N}=8$ nerves in $\mathrm{n}=6$ mice ( 3 female, 3 male) or old ( $\mathrm{N}=8$ nerves in $\mathrm{n}=6$ mice ( 3 female, 3 male) mice. Data from female mice is represented by blue circles and male mice by red squares).

\section{Supplemental Fig. 2}

No significant difference was observed between the patient's age and cytokine levels found within respective appendicitis supernatants. (A-E) Scatter plots and linear regression illustrating the lack of correlation between age and supernatant cytokines levels for (A) IL-1 $\beta$; (B). IL-2; (C). IL-6; (D) CXCL8; and (E) TNF- $\alpha$ ). The sex of the patients from which inflamed appendix were obtained is highlighted by blue circles for female patients and red squares for male patients. Statistical analysis performed using Spearman's correlations; $p>0.05$.

\section{Supplemental Fig. 3}

The multiunit colonic nerve response to luminal distension (0 to $80 \mathrm{mmHg}$ ) is blunted at noxious distending pressures $(40-80 \mathrm{mmHg}$ ), in tissue from old male and female mice compared with young male and female mice. (A) Line graphs showing the significant decrease in the afferent response to luminal distension in (i) tissue from 
old male mice ( $\mathrm{N}=3$ nerves in $\mathrm{n}=3$ mice; filled circles) compared with young male mice ( $N=3$ nerves in $n=3$ mice; open circles) and (ii) tissue from old female mice ( $N=4$ nerves in $n=4$ mice; filled circles) compared with young male mice ( $N=4$ nerves in $n=4$ mice; open circles). By contrast tissue compliance was increased at all distending pressures in tissue from old male and female mice compared with young male and female mice. (B) Line graphs showing the significant increase in tissue compliance to ramp distension of the colon, in (i) tissue from old male mice $(n=3$ mice; filled circles) compared with young male mice ( $n=3$ mice; open circles) and (ii) tissue from old female mice ( $n=4$ mice; filled circles) compared with young female mice ( $n=4$ mice; open circles).

Data is expressed as mean \pm SEM values, and statistically compared by 2-way ANOVA with Bonferroni's post hoc test, ${ }^{*} p<0.05,{ }^{* *} p<0.01,{ }^{* *} p<0.005$ ). 
Supplemental Figure 1

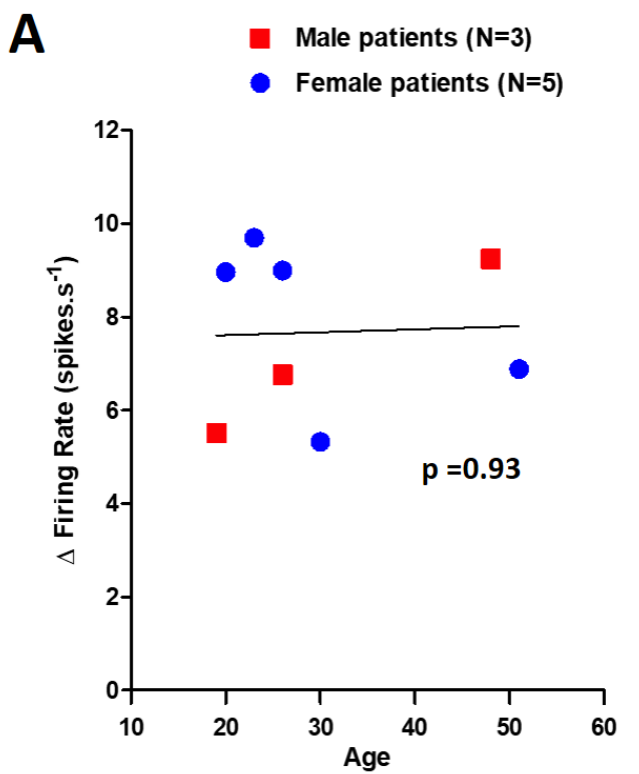

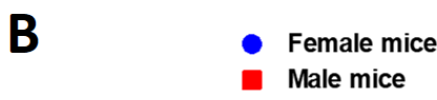

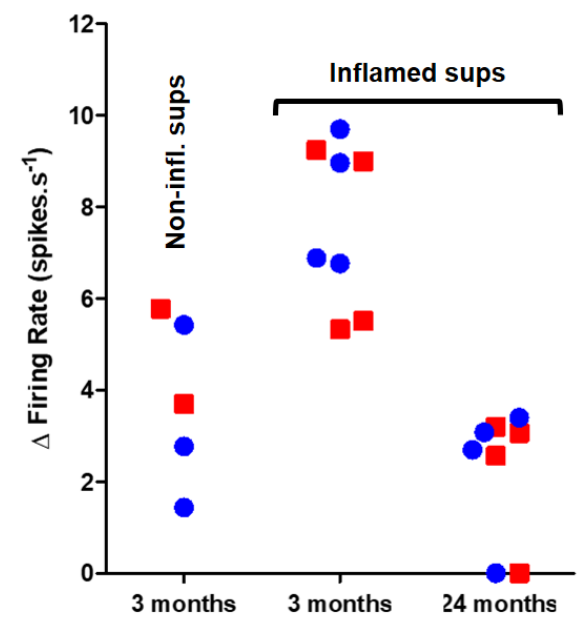


Supplemental Figure 2

A

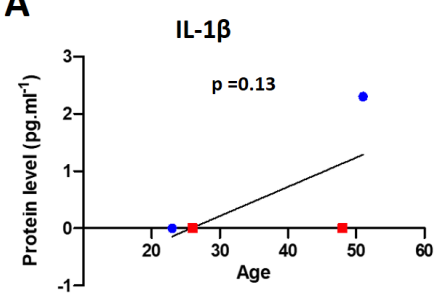

B
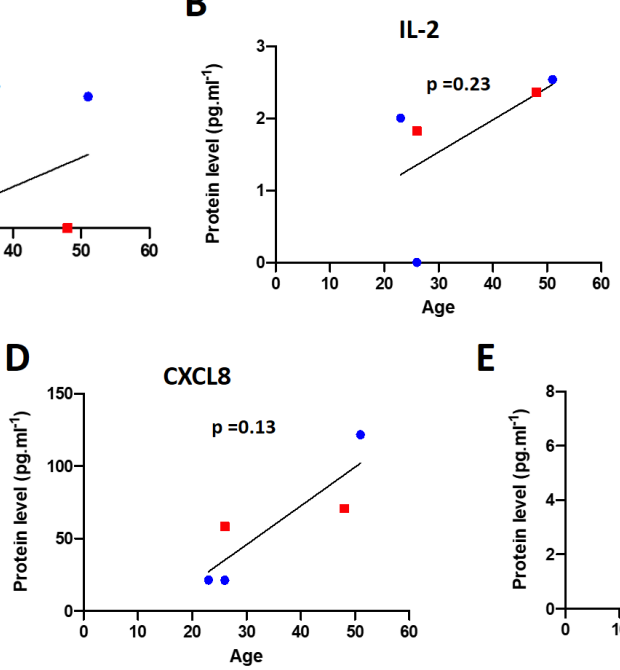

C

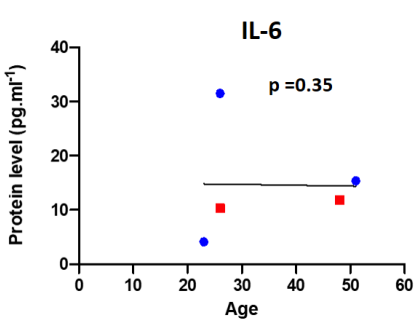

E

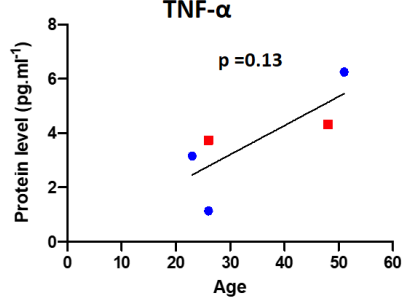


Supplemental Figure 3

A

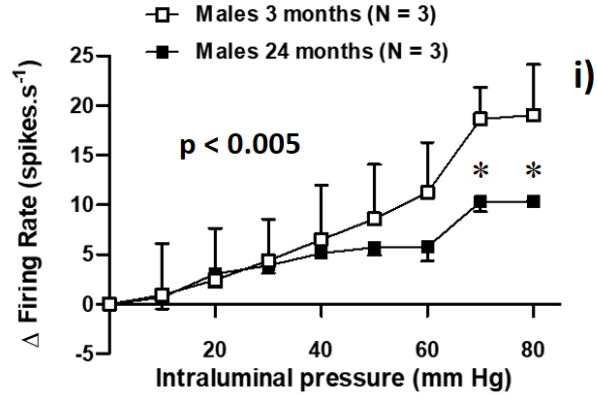

- Females 3 months $(\mathrm{N}=4)$

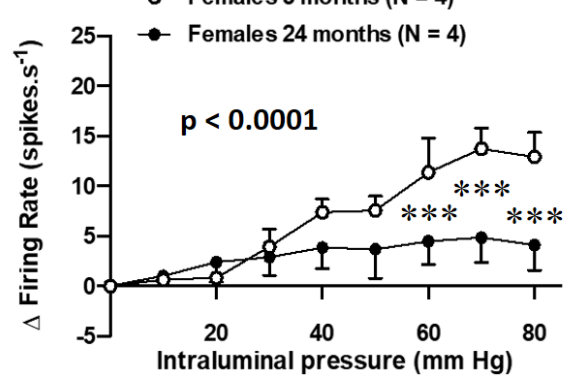

B

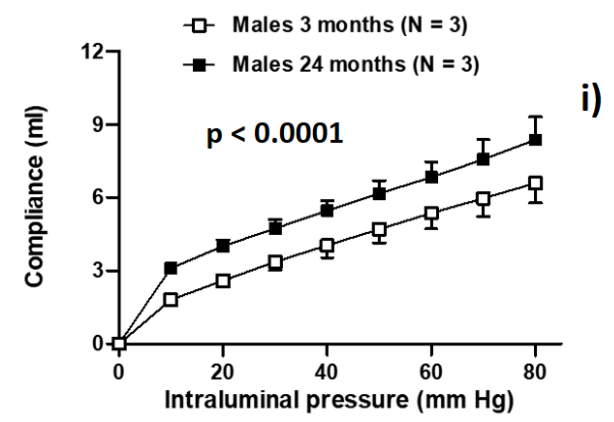

ii)

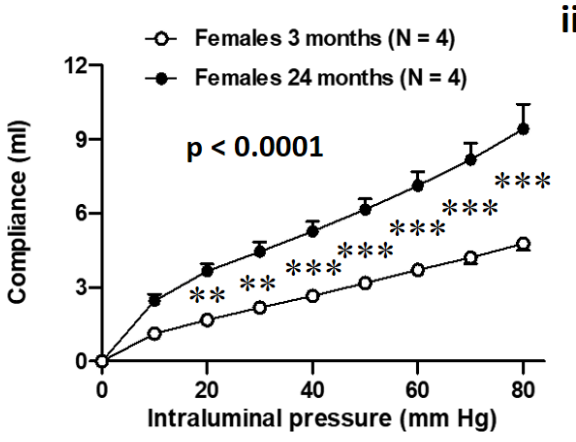

ii) 